\title{
Article \\ Numerical Investigation of Progressive Slope Failure Induced by Sublevel Caving Mining Using the Finite Difference Method and Adaptive Local Remeshing
}

\author{
Jingzhi Tu ${ }^{1}$, Yanlin Zhang ${ }^{1,2}$, Gang Mei ${ }^{1, *}$ and Nengxiong $\mathrm{Xu}^{1, *}$ \\ 1 School of Engineering and Technology, China University of Geosciences (Beijing), Beijing 100083, China; \\ tujingzhi@cugb.edu.cn (J.T.); ylzhang627@163.com (Y.Z.) \\ 2 BGI Engineering Consultants Ltd., Beijing 100083, China \\ * Correspondence: gang.mei@cugb.edu.cn (G.M.); xunengxiong@cugb.edu.cn (N.X.)
}

check for updates

Citation: Tu, J.; Zhang, Y.; Mei, G.; $\mathrm{Xu}, \mathrm{N}$. Numerical Investigation of Progressive Slope Failure Induced by Sublevel Caving Mining Using the Finite Difference Method and Adaptive Local Remeshing. Appl. Sci. 2021, 11, 3812. https://doi.org/ 10.3390/app11093812

Academic Editor: Susana

Lopez-Querol

Received: 6 April 2021

Accepted: 20 April 2021

Published: 23 April 2021

Publisher's Note: MDPI stays neutral with regard to jurisdictional claims in published maps and institutional affiliations.

Copyright: (c) 2021 by the authors. Licensee MDPI, Basel, Switzerland. This article is an open access article distributed under the terms and conditions of the Creative Commons Attribution (CC BY) license (https:/ / creativecommons.org/licenses/by/ $4.0 /)$.

\begin{abstract}
Slope failure induced by sublevel caving mining is a progressive process, resulting in the large deformation and displacement of rock masses in the slope. Numerical methods are widely used to investigate the above phenomenon. However, conventional numerical methods have difficulties when simulating the process of progressive slope failure. For example, the discrete element method (DEM) for block systems is computationally expensive and possibly fails for large-scale and complex slope models, while the finite difference method (FDM) has a mesh distortion problem when simulating progressive slope failure. To address the above problems, this paper presents a finite difference modeling method using the adaptive local remeshing technique (LREM) to investigate the progressive slope failure induced by sublevel caving mining. In the proposed LREM, (1) the zone of the distorted mesh is adaptively identified, and the landslide body is removed; (2) the updated mesh is regenerated by the local remeshing, and the physical field variables of the original computational model are transferred to the regenerated computational model. The novelty of the proposed method is that (1) compared with the DEM for block systems, the proposed LREM is capable of modeling the progressive slope failure in large-scale rock slopes; (2) the proposed method is able to address the problem of mesh distortion in conventional FDM modeling; and (3) compared with the errors induced by the frequent updating of the mesh of the entire model, the adaptive local remeshing technique effectively reduces calculation errors. To evaluate the effectiveness of the proposed LREM, it is first used to investigate the failure of a simplified slope induced by sublevel caving mining. Moreover, the proposed LREM is applied in a real case, i.e., to investigate the progressive slope failure induced by sublevel caving mining in Yanqianshan Iron Mine.
\end{abstract}

Keywords: progressive slope failure; sublevel caving mining; FDM; distorted mesh; adaptive local remeshing

\section{Introduction}

Slope failures are natural phenomena induced either by (1) natural factors, such as rainfall, changes in the groundwater level [1], loss of vegetation, and earthquakes, or by (2) human activities, such as additional loading and construction work at the top of slopes, excavation at the toe, and underground mining [2]. The methods of underground mining include the room and pillar mining method, caving method, and joint mining method. As one of the caving methods, sublevel caving using the filling of post-mining space to control geo-stress is a highly efficient, commonly used, top-down, underground bulk mining method. During underground mining, such as sublevel caving mining, progressive slope failure may be triggered. There are a variety of landslide classifications. Some types of slopes remain dormant after failure, while others show progressive or delayed failure in response to a disturbance. The progressive slope failure induced by sublevel caving mining will occur many times with the progress of the excavation. The slope experiences 
a cyclic process that cycles between a stable-unstable-stable-unstable condition; that is, intermittent instability.

To reduce the damage of slope failures on infrastructure and human life, numerical modeling methods are crucial for predicting and analyzing slope failure. These numerical methods typically fall into two categories: (1) continuum-based methods, such as the finite element method (FEM) and finite difference method (FDM), and (2) discontinuum-based methods, such as the material point method (MPM) and discrete element method (DEM).

The DEM is a powerful numerical modeling technique used to simulate discontinuous rock mass movement and failure [3,4]. Souley and Homand [5] used the DEM for block systems to study the failure and characteristics of jointed rock slopes. The MPM has also been widely used to analyze and simulate the deformation and failure of slopes [6-8]. However, the DEM is time-consuming and the performance of DEM is usually limited by computing capacity. When analyzing the deformation and failure of a large-scale slope, the DEM is quite computationally expensive. The MPM discretizes the continuum into a group of Lagrange particles with information, such as mass, velocity, position, and stress, and the processes of solving momentum equations and computing spatial derivatives are conducted on the Euler background mesh. When the particles pass through the background mesh, the gradient of the interpolation function will not be close to zero, resulting in a strong disturbance of the particle stress and cell-crossing noise. Therefore, for the modeling of large-scale rock slopes, the MPM is numerically unstable due to a large number of particles passing through the background mesh.

The FDM and FEM are also commonly used to analyze slope failure. Compared with the DEM, they are more computationally efficient. However, both the FEM and FDM are mesh-dependent. When meshes undergo a large deformation, mesh-dependent numerical simulation methods experience problems, such as a distorted mesh, making the calculation impossible [9]. To address this problem, Elmo et al. [10] and Vyazmensky et al. [11] used a hybrid FEM-DEM approach to analyze and evaluate the stability of a slope in open-pit and underground mining. Mohammadi and Taiebat [2] used the h-adaptive mesh refinement technique to simulate the deformation and damage of a slope by frequently updating the slope geometry. Sun et al. [12] combined the Hoek-Brown strength reduction technique and the FEM to evaluate and analyze the slope stability.

On the other hand, the limit equilibrium method and strength reduction method (SRM) [13] are also widely used to evaluate the slope stability and determine the slip surface. However, for the progressive slope failure induced by sublevel caving mining, this strategy needs to reconstruct the model repeatedly according to the terrain conditions after the landslide, which is inefficient. In addition, it cannot analyze the stress and strain of the slope during the failure process.

In summary, there are some critical issues that must be addressed when these numerical methods are used to simulate progressive slope failure. (1) The DEM is time-consuming and the performance of the DEM is usually limited by computing capacity. Thus, the application of DEM in large-scale engineering is limited, i.e., when analyzing the deformation and failure of a large-scale slope, the DEM is quite computationally expensive or may even fail. (2) In the MPM, there is a strong disturbance of the particle stress and cell-crossing noise when the particles pass through the background mesh, resulting in numerical instability when the MPM is used to simulate large-scale rock slope. (3) Both the FEM and FDM are mesh-dependent. When meshes undergo a large deformation, mesh-dependent numerical simulation methods experience problems, such as a distorted mesh, i.e., when the FEM or FDM is used to simulate progressive slope failure, the problem of mesh distortion will appear, making the calculation impossible.

To specifically address the above problems, in this paper, the finite difference modeling method using the adaptive local remeshing technique (LREM) is proposed to analyze and predict the process of a progressive slope failure induced by sublevel caving mining. In the proposed LREM, (1) on the basis of the slip surface determined by the maximum shear strain increment belt method, the zone of the distorted mesh is identified adaptively 
and the landslide body is removed; (2) the updated mesh is regenerated by the local remeshing technique and the physical field variables of the original computational model are transferred to the regenerated computational model.

The novelty of the proposed method is that (1) compared with the DEM, the proposed LREM is capable of simulating progressive slope failure in large-scale rock slopes; (2) the proposed method is able to address the problem of mesh distortion in conventional FDM modeling and prevent numerical modeling from non-convergence; and (3) the proposed method regenerates the distorted meshes and part of the available meshes, resulting in a slight decrease in accuracy. However, compared with the errors induced by frequent updating of the mesh of the entire model, the adaptive local remeshing technique effectively reduces the errors.

The main contributions of this paper can be summarized as follows:

(1) The LREM is proposed to simulate the progressive failure of a simplified slope induced by sublevel caving mining, and its results are compared with those acquired using the SRM and FDM, which can verify the effectiveness of the LREM.

(2) The slope failure of the Yanqianshan Iron Mine is analyzed and predicted using the proposed method, which can be applied as a reference for the sublevel caving mining plan of this mine.

The rest of this paper is organized as follows. Section 2 introduces the analysis and conclusion of slope failure due to the sublevel caving mining from previous researches. Section 3 introduces the proposed method in detail. In Section 5, the proposed method is applied to simulate the slope failure of a real iron mine. Section 6 discusses the advantages and shortcomings of the proposed method. Section 7 draws several conclusions.

\section{Progressive Slope Failure Induced by Sublevel Caving Mining}

During the sublevel caving mining of ore bodies, the filling layer incrementally moves downward. For example, as illustrated in Figure 1, when mining the $(n-1)$ th layer, its goaf will be filled with loose deposits. The loose deposits become the filling layer of the $n$th layer. When mining the $n$th layer, the filling layer will move downward, and the goaf will be filled with loose deposits. After completing the mining of the $n$th layer, the filling layer will move completely to the goaf of the $n$th layer. In this study, the nonpillar sublevel caving method was used in all cases.

When the ore bodies lie quite deeply, exploitation by open-pit mining is no longer economically reasonable, especially in this case. Therefore, for most iron ores, mining transitions from open pits to underground areas after completing open-pit mining. When open-pit mining is completed, the surface will form a deep open-pit slope, and the mine is transformed into underground mining due to the economic unreasonableness of open-pit mining, where the free surface of the slope increases, and the factor of safety (FOS) of the slope decreases. The factors affecting the stability of the slope include the topography, groundwater, rainfall, tectonic movements, and earthquakes $[14,15]$. Second, the slope stability has dynamic characteristics because of the continuous changes in the structure of the rock mass, geometry of the slope, height of the groundwater level, and release of stress during the underground mining process. The scale of a landslide is different under different geological conditions. For rock masses with a higher stability, the rock mass tends to move toward the goaf when the excavation depth is deeper. In the case of broken rock masses, a local landslide can occur [16].

Figure 1 shows the process of progressive slope failure induced by sublevel caving mining. With the increase in the excavation depth, the slope experiences a cyclic process that cycles between a stable-unstable-stable-unstable state [11]. In the initial stage of sublevel caving mining, the filling layer gradually moves downward to form a collapse groove. At this time, the slope is stable due to the small depth of the collapse groove; that is, the height difference between the top of the filling layer and the original pit bottom is small. Then, with the increase in the excavation depth, the depth of the collapse groove gradually increases. The higher potential-energy difference leads to a gradual increase in 
the displacement of the rock mass on both sides of the collapse groove, a gradual increase in the maximum principal stress of the slope, and a decrease in the stability coefficient of the slope. When the FOS of the slope is the lowest, the slope is unstable and the rock mass on both sides of the collapse groove will slide to the center of the collapse groove, thus inducing a retrogressive landslide, as shown in Figure 1. Finally, the slope returns to a stable state after the landslide body completely falls.

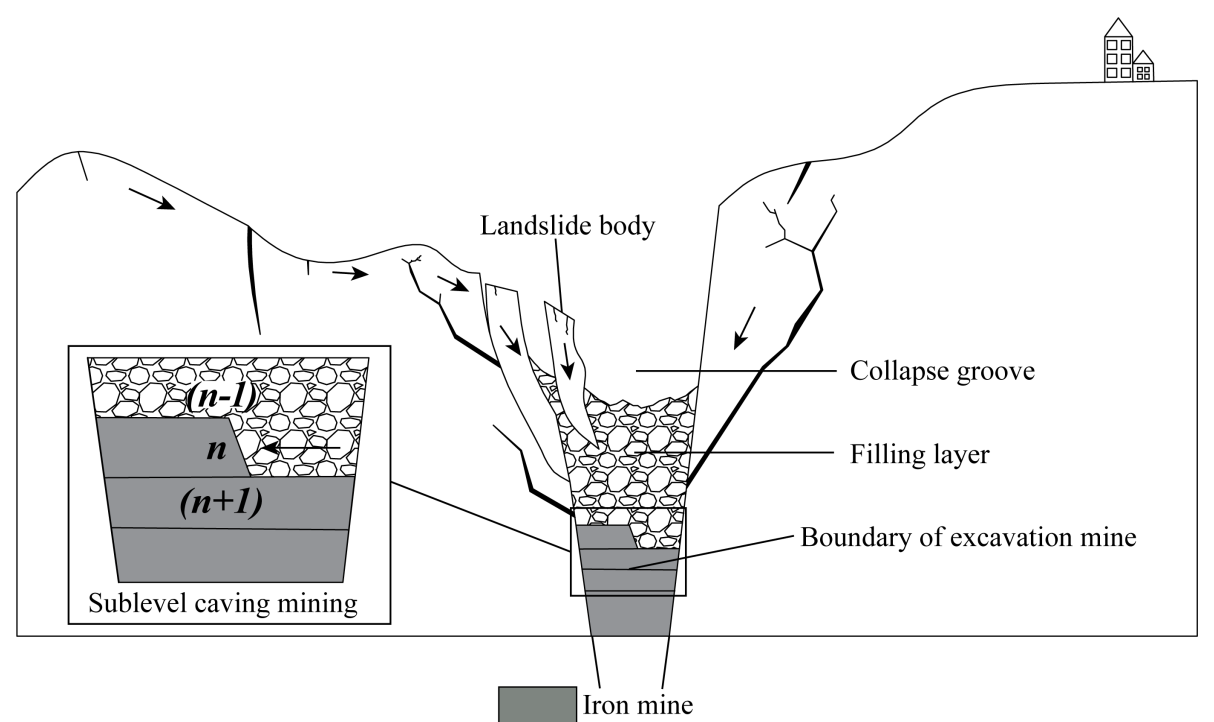

Figure 1. An illustration of the progressive slope failure induced by the sublevel caving mining.

With the gradual increase in mining depth, the above process occurs repeatedly, and the rock masses surrounding the handing and heading sides of the goaf continuously slide to the center of the collapse groove. The thickness of the filling layer will increase as the rock masses slide into the collapse groove. According to the ore draw ellipsoid theory, the collapse groove disappears or the thickness of the filling layer increases, leading to an increase in ore loss and ore dilution in the mining process [17]. Thus, in the mining process, because of the requirement of the nonpillar sublevel caving method, the collapsed rock is treated manually to keep the thickness of the filling layer from increasing.

\section{Methodology}

\subsection{Overview}

The progressive slope failure induced by sublevel caving mining is a cyclic process, resulting in the large deformation and displacement of rock masses in a large-scale rock slope. The DEM and FDM are widely used to investigate slope failure. However, the DEM for block systems is quite computationally expensive or even possibly fails for largescale and complex slope models; the FDM has a mesh distortion issue when simulating progressive slope failure.

To address the above problem, in this paper, the LREM is proposed to analyze and predict the process of progressive slope failure induced by sublevel caving mining. As illustrated in Figure 2, in the proposed LREM, (1) the most dangerous slip surface can be obtained using the maximum shear strain increment belt method when the slope is unstable; (2) the surface triangular meshes in the zone requiring remeshing can be acquired adaptively; (3) the landslide body can be easily removed according to the most dangerous slip surface; (4) according to the surface triangular meshes of the zone, the tetrahedral meshes are regenerated for the zone requiring remeshing; (5) the physical field variables of the original computational model are transferred to the regenerated computational model; and (6) the regenerated computational model is used to recalculate the interactions in the model. 


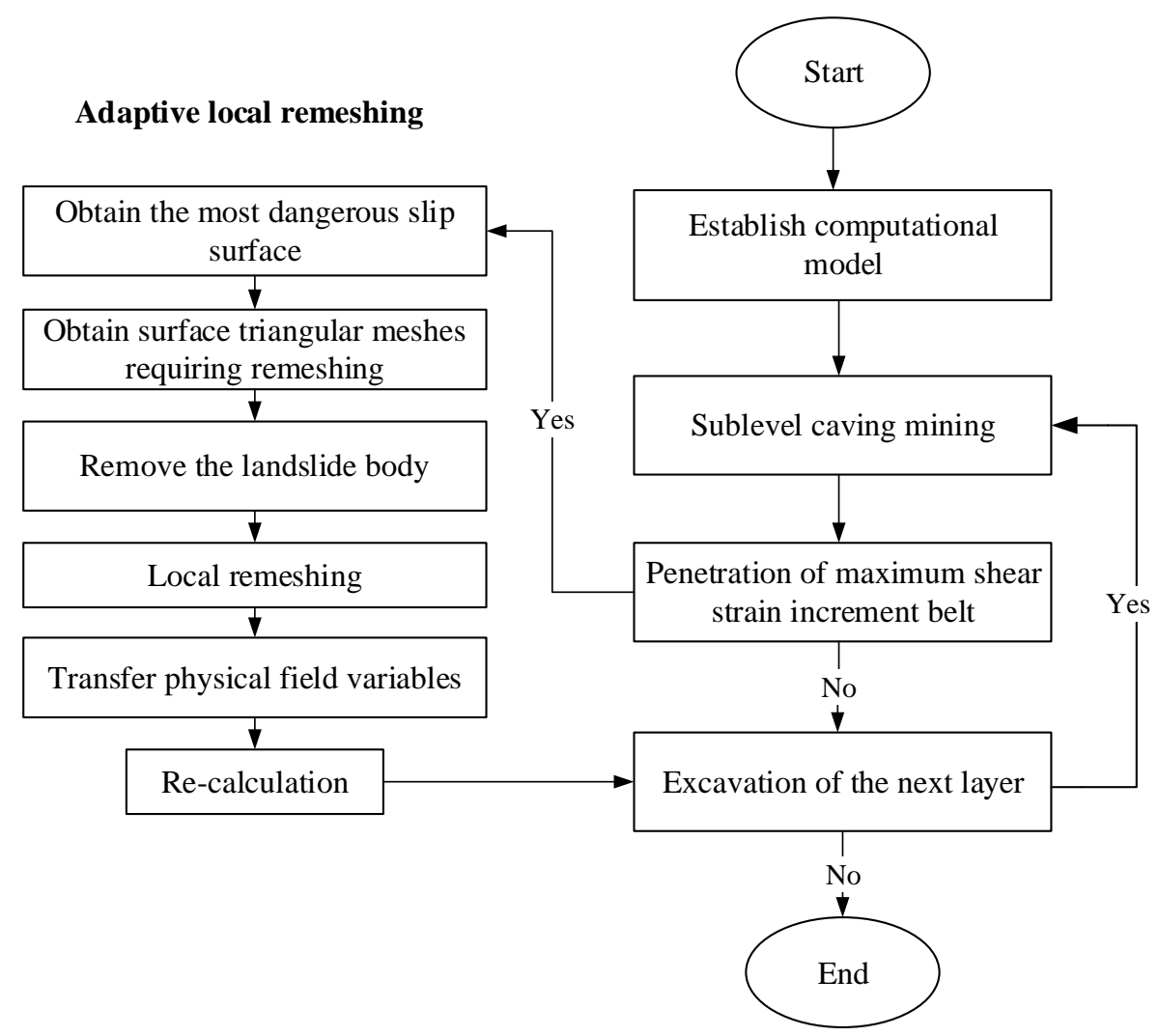

Figure 2. The flowchart of the proposed LREM for the progressive slope failure induced by the sublevel caving mining.

\subsection{Acquisition of the Most Dangerous Slip Surface}

\subsubsection{Searching for the Slip Surface}

A key step in slope stability analyses is to determine the location of the most dangerous slip surface. This can be done using the limit equilibrium method [18,19], numerical analysis methods $[20,21]$, the graphic method [22], dichotomy, or artificial intelligence methods $[23,24]$.

In this study, the maximum shear strain increment belt method is used to determine the most dangerous slip surface. First, the FDM is used to simulate ore body excavation until the slope reaches a critical state, i.e., the numerical calculation does not converge, and the model has a penetration of maximum shear strain increment belt. Then, the coordinates at the maximum point of the shear strain increment are obtained. The least-squares method is used to optimize the discrete points, and the optimized points are connected to obtain the shape and position of the slip surface

\subsubsection{Acquisition of the Slip Surface}

To illustrate the process of the proposed method, a simplified slope model is used (Figure 3). In the model, the thickness, width and length of each excavation are determined to be 18,88 , and $300 \mathrm{~m}$, and the mechanical parameters of the rock mass and the ore body are listed in Table 1. The boundary condition in the numerical analysis is set mainly in terms of the displacement. In the simplified model, the full constraint is set at $y=-600 \mathrm{~m}$, i.e., the displacement in the three directions is limited. At $x=0 \mathrm{~m}$ and $x=800 \mathrm{~m}$, the displacement constraint in the $\mathrm{x}$-direction is set; at $z=0 \mathrm{~m}$ and $z=300 \mathrm{~m}$, the displacement constraint in the $\mathrm{z}$-direction is set; the remaining positions are free boundaries. The constitutive model is Mohr-Coulomb. 


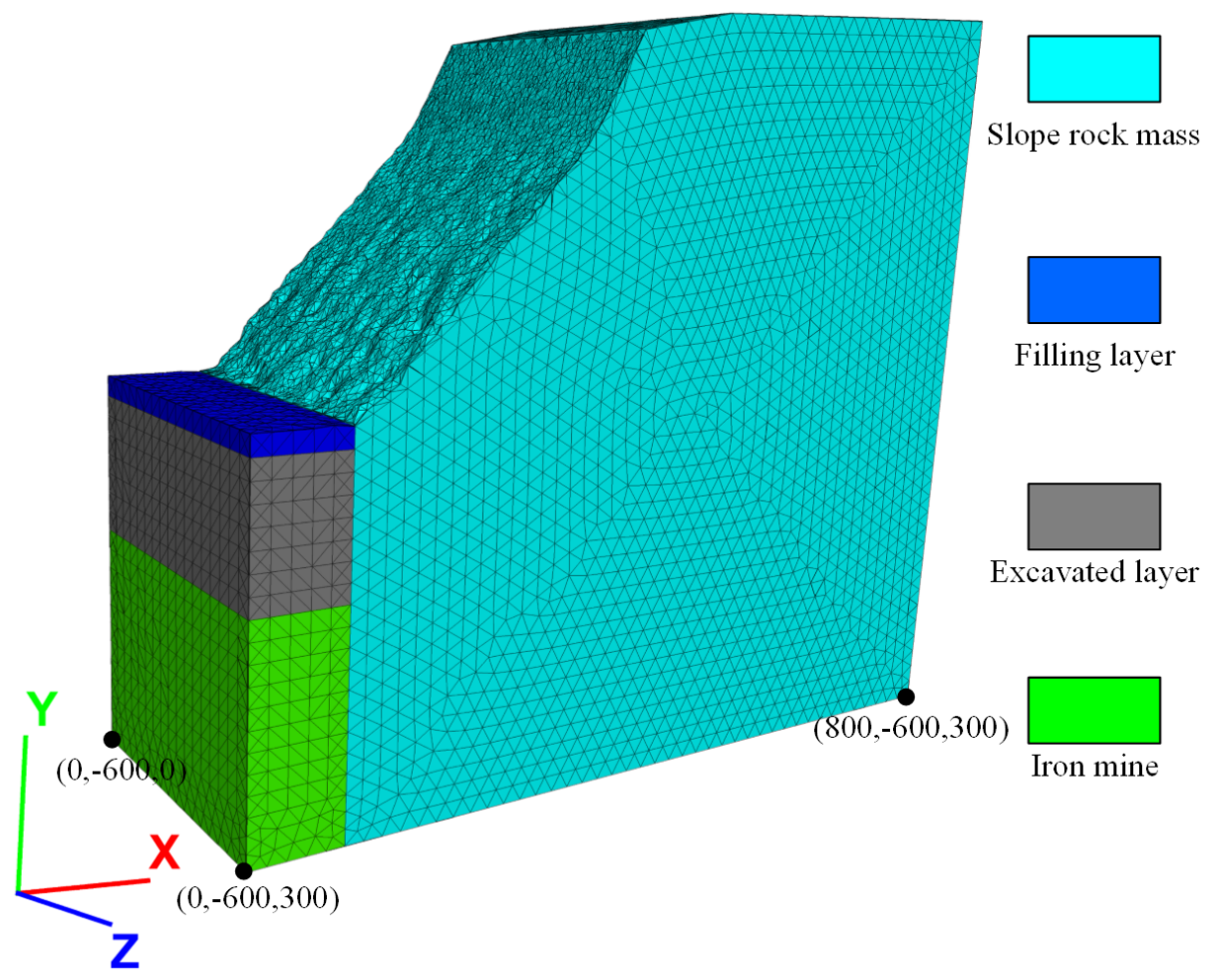

Figure 3. An illustration of the simplified slope model.

Table 1. Mechanical parameters of rock masses and soil (where $C$ is the cohesion $3, \varphi$ is the internal friction angle, $E$ is the young's modulus, $\mu$ is the Poisson's ratio, $\rho$ is the density).

\begin{tabular}{cccccc}
\hline Name & $\boldsymbol{C}(\mathbf{M P a})$ & $\boldsymbol{\varphi ( { } ^ { \circ } )}$ & $\boldsymbol{E}(\mathbf{G P a})$ & $\boldsymbol{\mu}$ & $\boldsymbol{\rho}\left(\mathbf{k g} / \mathbf{m}^{\mathbf{3}}\right)$ \\
\hline Iron Mine & 0.95 & 41 & 40 & 0.2 & 3100 \\
Slope Rock Mass & 0.45 & 39 & 18 & 0.23 & 2670 \\
Filling Layer & 0 & 25 & 6 & 0.32 & 1550 \\
\hline
\end{tabular}

When the eighth layer of the excavation is simulated, some meshes are stretched into distorted meshes along the slip surface, leading to the nonconvergence of the numerical calculation, which demonstrates that the slope is unstable, and the landslide slides along the slip surface. The maximum shear stress develops from the inside of the slope to the slope surface. Figure 4 shows the penetration of the maximum shear strain increment belt, which demonstrates that the slope becomes unstable when the ore body is excavated to the eighth layer.

The slip surface is acquired as follows:

(1) A vertical line is set at the position of the ore vein from the top position of the filling layer.

(2) Radiation is incrementally emitted from the vertical line toward the direction of the rock mass from the bottom of the vertical line.

(3) The mesh with the highest shear strain is obtained by comparing the magnitude of the shear strain increment of the meshes on the horizontal rays, and the centroid of the mesh with the highest shear strain is taken as the maximum shear strain increment point.

(4) The maximum shear strain increment points for all rays are determined. The results are indicated by the black and pink points in Figure 4.

(5) The stress concentration points near the foot of the slope (pink points in Figure 5) are ignored, and based on the general trend of the black points, reference points are 
added near the free surface of the slope and the top of the slope (yellow points in Figure 4).

(6) The least-squares method is used to adjust these points, and the optimized points are connected to form a smooth curve (Figure 4).

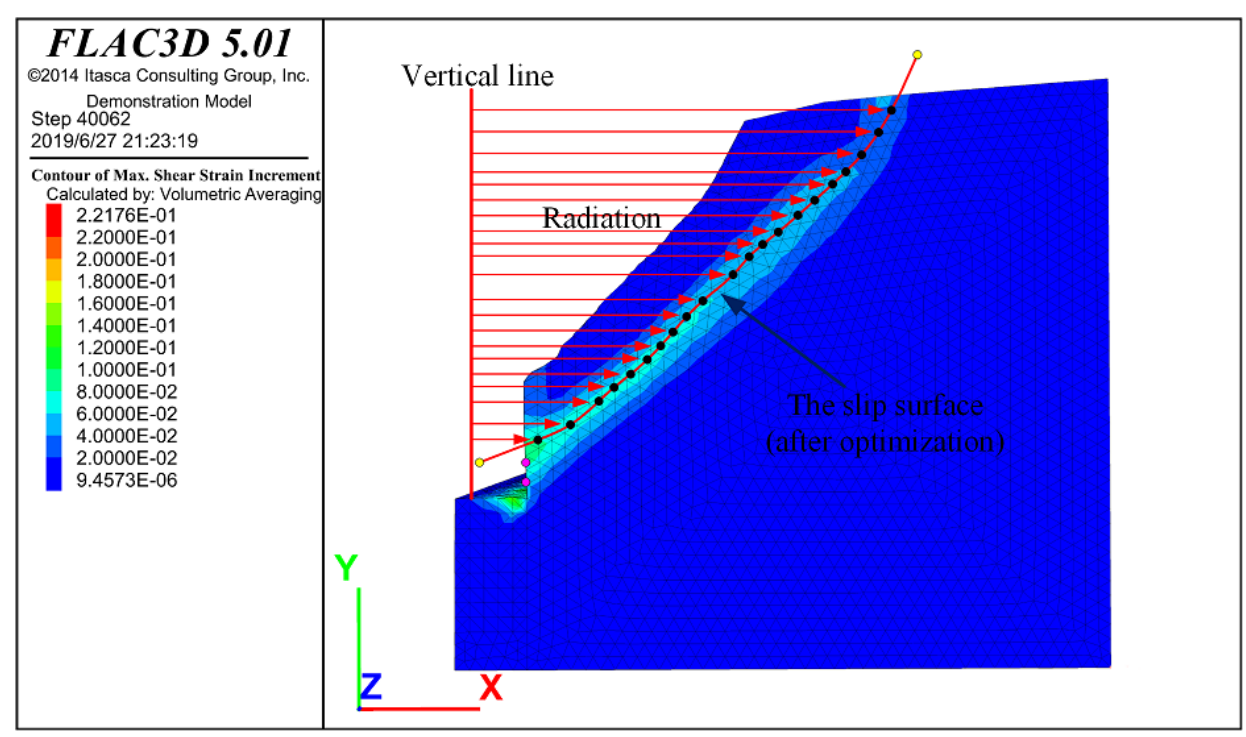

Figure 4. The sketch of determination of the slip surface.

\subsection{Acquisition and Adjustment of the Surface Triangular Mesh}

When the eighth layer of the excavation is simulated, the distorted mesh problem is introduced. To address this issue, we need to determine the location of the zone of the distorted mesh.

The mesh with excessive deformation is mainly composed of two parts with the following characteristics:

(1) The abovementioned mesh with excessive deformation is divided into two parts using the most dangerous slip surface.

(2) Part 1: This part is the landslide body between the slip surface and free surface. We can simulate a landslide by removing the landslide body.

(3) Part 2: This part of the mesh is located near the slip surface. A part of the mesh is stretched because of the landslide, and the deformation of the mesh is either considerable or the mesh is completely deformed. Therefore, this part of the mesh requires remeshing.

According to the above characteristics, we used the wedge method to determine the location of the distorted meshes and to retain the original nodes as much as possible (Figure 5a). The following steps are included in the wedge method:

(1) Determine the points $J, K$, and $L$ at the outer edge of the maximum shear increment belt.

(2) Form a sector with $\mathrm{O}$ as the center.

(3) Form the wedge space. The distortion zone is divided into a landslide body portion and a remeshing portion through the most dangerous slip surface. 


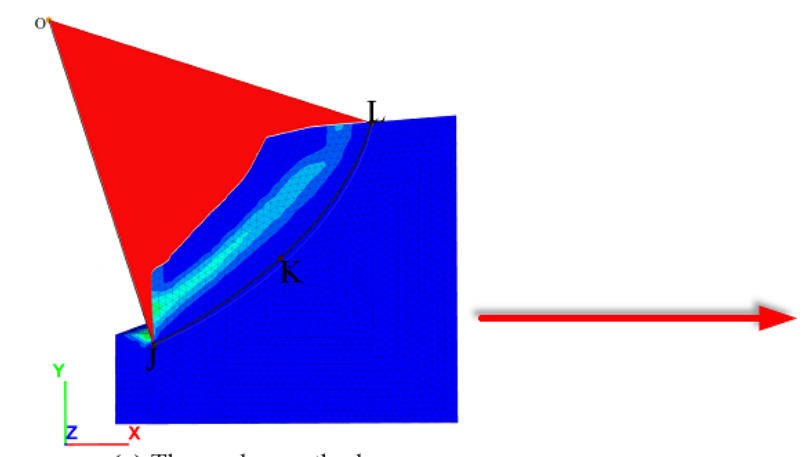

(a) The wedge method

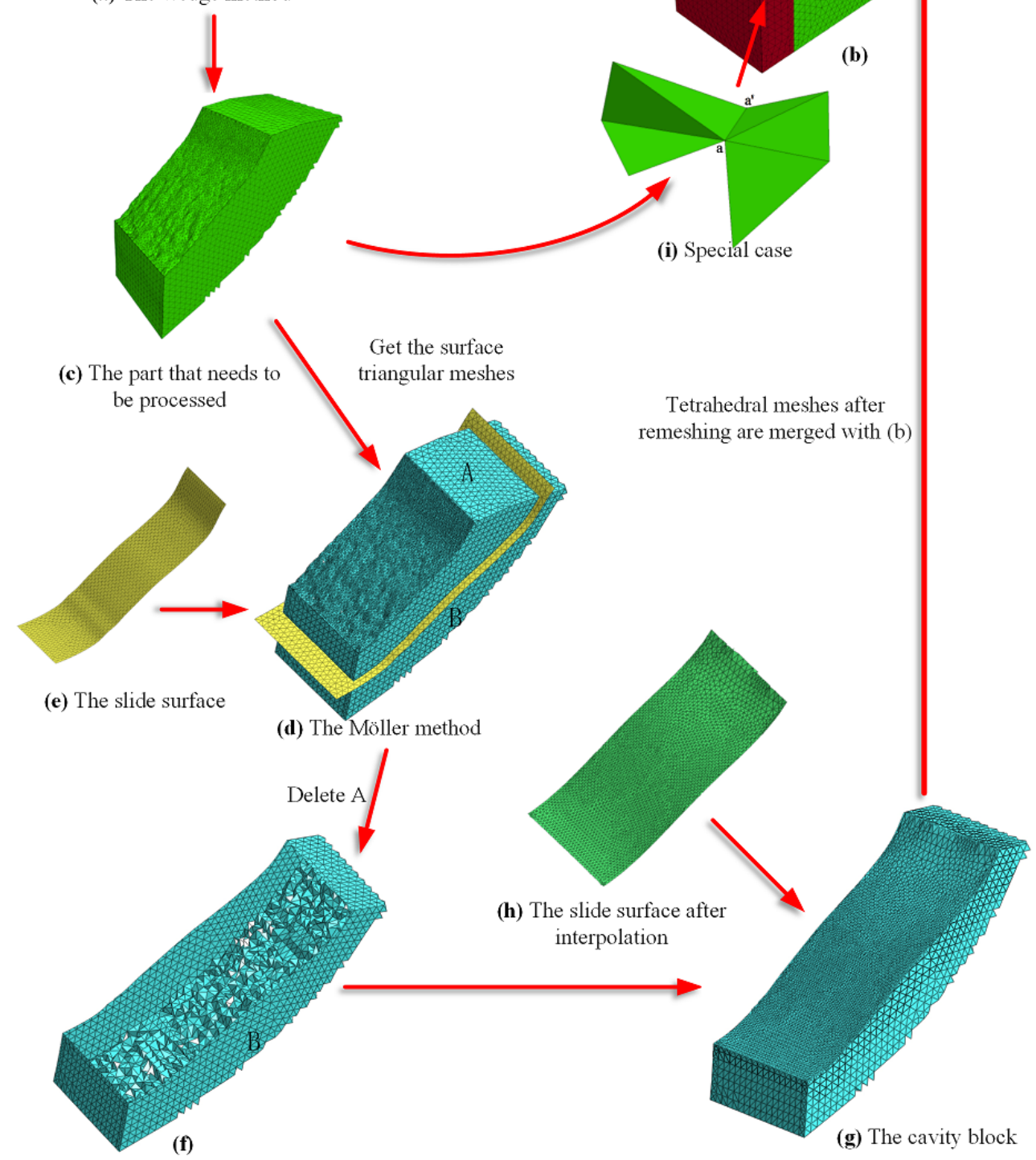

Figure 5. The working process of adaptive local remeshing $(\mathbf{a}-\mathbf{c})$ : the wedge method is used to obtain the part that has distorted meshes; $(\mathbf{c}, \mathbf{d})$ : the surface triangular meshes requiring remeshing are obtained, and the Möller method is used to obtain the intersections between the triangular meshes to realize the intersection of the slip surface with a large deformation triangular mesh; $(\mathbf{d}-\mathbf{f})$ : after the intersection of the slip surface with a large deformation triangular mesh is obtained, part A is deleted to realize the removing of the landslide body (e): the most dangerous slip surface is obtained by the maximum shear strain increment belt method); $(\mathbf{b}-\mathbf{f})$ : the tetrahedral meshes are obtained by the local remeshing according to $(\mathbf{g})$ consisting of $(\mathbf{f}, \mathbf{h})$, and the tetrahedral meshes are merged with the remaining meshes $(\mathbf{b}) ;(\mathbf{i})$ : the tetrahedral meshes satisfying the special case are directly merged with (b). 


\subsubsection{Acquisition of the Surface Triangular Mesh}

(1) Features of the tetrahedral mesh

The tetrahedral mesh in Figure $5 \mathrm{c}$ can be divided into two parts. One part is the internal tetrahedral mesh, of which the surface triangular mesh must be shared by two tetrahedral meshes. The other part is the superficial tetrahedral mesh. The tetrahedral mesh in this part has at least one nonshared surface. In these superficial meshes, if any one of the surfaces of a tetrahedral mesh appears only once, the surface can be used as part of the surface triangular mesh.

(2) Special case

One problem that is introduced by the superficial tetrahedral mesh is that for the surface of the triangular mesh, some edges are shared by more than two triangles, as shown in Figure 5i. The edges are shared by four triangles. Therefore, it is necessary to ensure that any edge of the surface triangular mesh is shared by only two triangles. Otherwise, the tetrahedral mesh that does not satisfy the conditions is classified into the meshes of Figure $5 b$, and this rule is taken as a judgment condition.

\subsubsection{Adjustment of the Surface Triangular Mesh}

After acquisition of the surface triangular mesh, it is necessary to check whether the order of all surface triangular mesh nodes is the same. For two triangles with a common edge, if the order of the nodes is counterclockwise, as shown in Figure 6, the order of the nodes of the left triangle is 1-2-4-1. The order of the right triangle is 2-3-4-2, where the ordering of the nodes of the common edge is reversed.

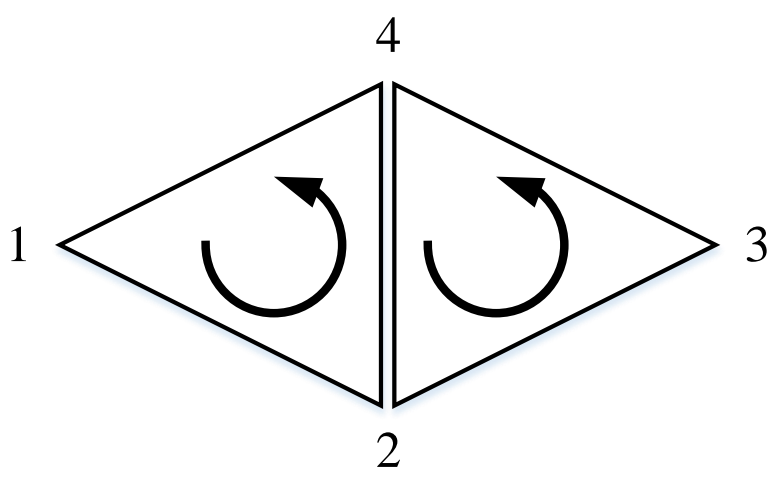

Figure 6. An illustration of the order of nodes.

The adjustment steps of the surface triangular mesh nodes are as follows:

Step 1: The order of the three nodes of a triangle is adjusted to be counterclockwise, and the triangle is marked as T1, indicating that the order of the nodes of the triangle has been adjusted.

Step 2: The neighboring triangles of T1 that have shared edges are searched. If the order of the shared edge nodes of the neighboring triangle is counterclockwise, the order of the nodes of the triangle is adjusted and the triangle is marked as T2.

Step 3: The neighboring triangles of $\mathrm{T} 2$ that have shared edges are searched. If the order of the shared edge nodes of the neighboring triangle is counterclockwise, the order of the nodes of the triangle is adjusted and the triangle is marked.

Step 4: This cycle is repeated until all the triangles are marked.

\subsection{Local Remeshing of the Distorted Mesh}

\subsubsection{Removal of the Landslide Body}

According to Section 3.3, the zone determined by the wedge method can be divided into two parts. To simulate the landslide, the landslide body (part A in Figure 5d) must be removed, and the rest of the mesh (part B Figure 5f) must be updated. We use the algorithm 
that intersects the slip surface and the surface triangular mesh obtained in Section 3.3 to remove the landslide body.

Two main methods are used to determine intersections between triangles. The first one is the scalar discriminant method. The intersection point is obtained after the intersection of the triangles is found using the Möller method [25] or the Tropp method [26]. The other method involves determining whether the triangles intersect by determining the sign of the calculation result using the Shen method [27] or the Guigue method [28]. Since the Möller method has better accuracy and is a mature program, we used the Möller method to obtain the intersections between the triangular meshes to realize the intersection of the slip surface with a large deformation triangular mesh (Figure $5 \mathrm{~d}$ ).

\subsubsection{Tetrahedral Mesh Remeshing}

The rest of the mesh (part B Figure 5f) must be combined with a suitable slip surface to form a complete surface. Then, the tetrahedral mesh is regenerated by the complete surface.

To obtain a suitable slip surface, according to the upper surface boundary of part B, the triangulated surface (Figure 5e) is interpolated using the Kriging interpolation method to form a new slip surface (Figure $5 \mathrm{~h}$ ), which is perfectly merged with part B. Finally, the new slip surface merges with part B, and the cavity block (Figure $5 \mathrm{~g}$ ) with triangular mesh surfaces should be tetrahedral.

After remeshing, the tetrahedral mesh is merged with the meshes shown in Figure $5 \mathrm{~b}$. There is a key issue that needs to be addressed. The boundary of part B needs to be obtained and is composed of boundary nodes. Mei et al. [29] proposed a high-efficiency differentiation method for the boundary point and the internal point. For example, for node $n_{0}$, shown in Figure 7 , its neighbors are nodes $\left\{n_{1}, n_{2}\right\},\left\{n_{2}, n_{3}\right\},\left\{n_{3}, n_{4}\right\},\left\{n_{4}, n_{5}\right\}$, $\left\{n_{5}, n_{6}\right\}$, and $\left\{n_{6}, n_{1}\right\}$. Each of its neighbors is recorded twice because of the calculation from two adjacent triangles. In other words, any edge containing an internal vertex would be shared by two adjacent triangles. Therefore, the basic idea behind determining the boundary vertices is straightforward: if all the neighbors of a vertex, for example, node $n_{0}$ in Figure 7, are recorded twice, the vertex is internal; otherwise, it is a boundary node.

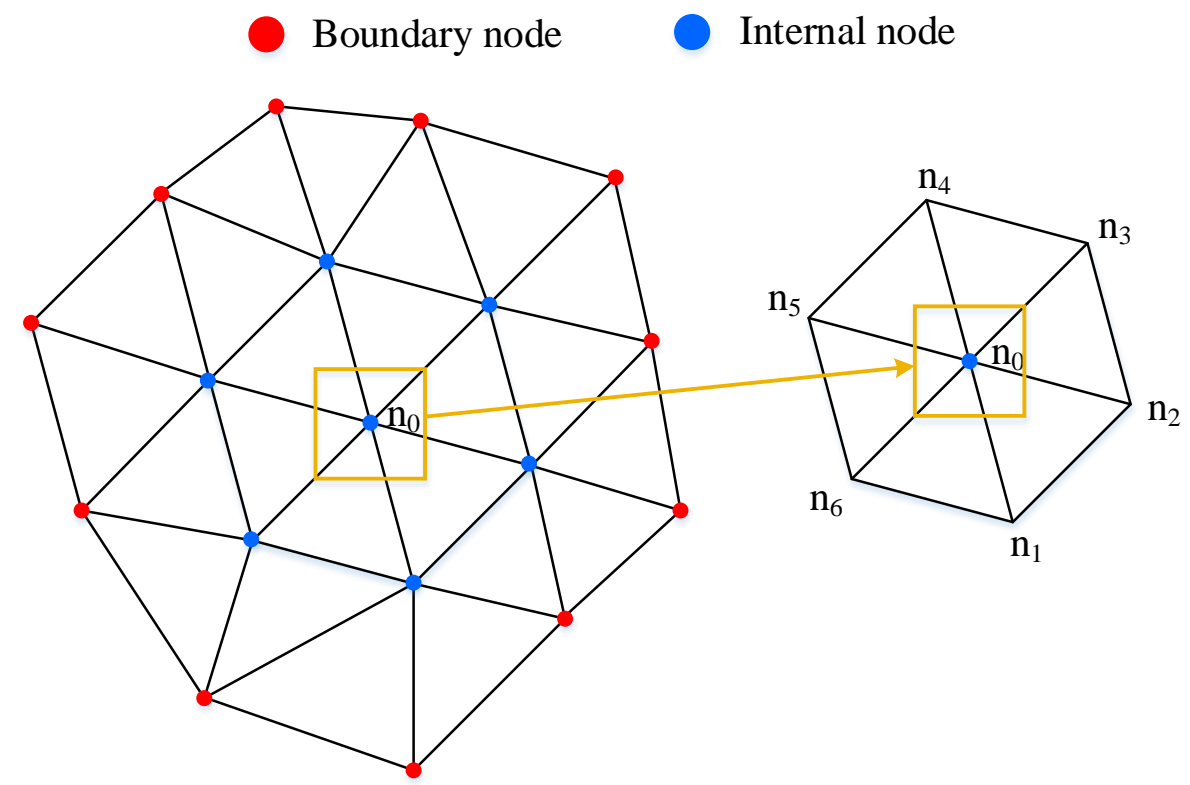

Figure 7. An illustration of determining boundary nodes according to neighbors. 


\subsection{Transfer of the Physical Field Variables}

As the position and topology of the mesh change after remeshing, the physical field variables of the old mesh are no longer applicable for the new mesh. Therefore, to ensure the continuity of the numerical calculations, new field values need to be interpolated according to the positions of the nodes.

The physical field variables in the FlAC ${ }^{3 \mathrm{D}}$ software are divided into node status information and mesh status information. In the FLAC ${ }^{3 \mathrm{D}}$ software, there are functions for output and input physical field variables.

For the transfer of the mesh field variables, for example, the transfer of the stress can be carried out in four steps:

(1) Transfer the stress of the old meshes to the old nodes to obtain the equivalent mesh physical field variables of the old nodes.

(2) Determine the relationship between the new node and the old mesh. This step requires the new mesh node to be inside the old mesh.

(3) Transfer the equivalent mesh stresses of the old nodes to the new nodes. The equivalent mesh stresses of the nodes and the shape function can be used to interpolate the value of the stresses at any position in the mesh; see Equations (1) and (2).

$$
u=[N] \bullet\left\{\begin{array}{l}
u_{i} \\
u_{j} \\
u_{k} \\
u_{l}
\end{array}\right\}
$$

where [N] is the shape function of the original mesh, and $u_{i}, u_{j}, u_{k}$, and $u_{l}$ are the physical field variables of the original mesh.

$$
\left[N_{0}\right]=\left[\begin{array}{llll}
1 & x & y & z
\end{array}\right] \bullet\left[\begin{array}{llll}
1 & x_{1} & y_{1} & z_{1} \\
1 & x_{2} & y_{2} & z_{2} \\
1 & x_{3} & y_{3} & z_{3} \\
1 & x_{4} & y_{4} & z_{4}
\end{array}\right]
$$

where $\left[N_{0}\right]$ is the shape function of the new node; $(x, y, z)$ are the coordinates of the new node; and $\left(x_{i}, y_{i}, z_{i}\right)$ are the coordinates of the original node, $i=1,2,3,4$.

(4) Acquire the physical field variables of the new meshes; see Equation (3).

$$
\bar{\varepsilon}_{i}^{\text {Ele }}=\frac{\left(\sum_{j=1}^{4} \bar{\varepsilon}_{j}^{\text {Node }}\right)}{4}
$$

where $\bar{\varepsilon}_{j}^{\text {Node }}$ is the equivalent physical field variables of node $j$ of mesh $i ; \bar{\varepsilon}_{i}^{E l e}$ is the physical field variables of mesh $i$.

The node field variables can be transferred through the second and third steps described above.

\section{Verification}

To verify the correctness of the regenerated computational model, the numerical modeling step is recalculated. As shown in Figure 8, under gravity, when boundary conditions and mechanical parameters (Table 1) are unchanged, the calculation converges, and the plastic zone distribution range is small, indicating that the landslide simulation is realized. After the landslide occurs, the unstable zone is eliminated, and the slope is in a stable state.

To verify the effectiveness of the proposed LREM, the results using the proposed LREM for modeling the progressive failure of the simplified slope induced by sublevel caving mining are compared with those obtained using the FDM and SRM in terms of 
stability. A frequently used strategy for determining the FOS of a slope is the SRM, which can calculate the safety factor accurately; however, it cannot simulate the deformation and failure of a slope. As listed in Table 2, when the first seven layers are excavated, the FOS $>1$, which is calculated using the FDM and SRM. At this time, the maximum shear strain increment belt is not connected, the calculation converges, and the slope is in a stable state. When the eighth layer is excavated and FOS $=1$, penetration of the maximum shear strain increment belt occurs, the calculation does not converge, and the slope is in an unstable state. After using the adaptive local remeshing technique, the FOS $>1$.

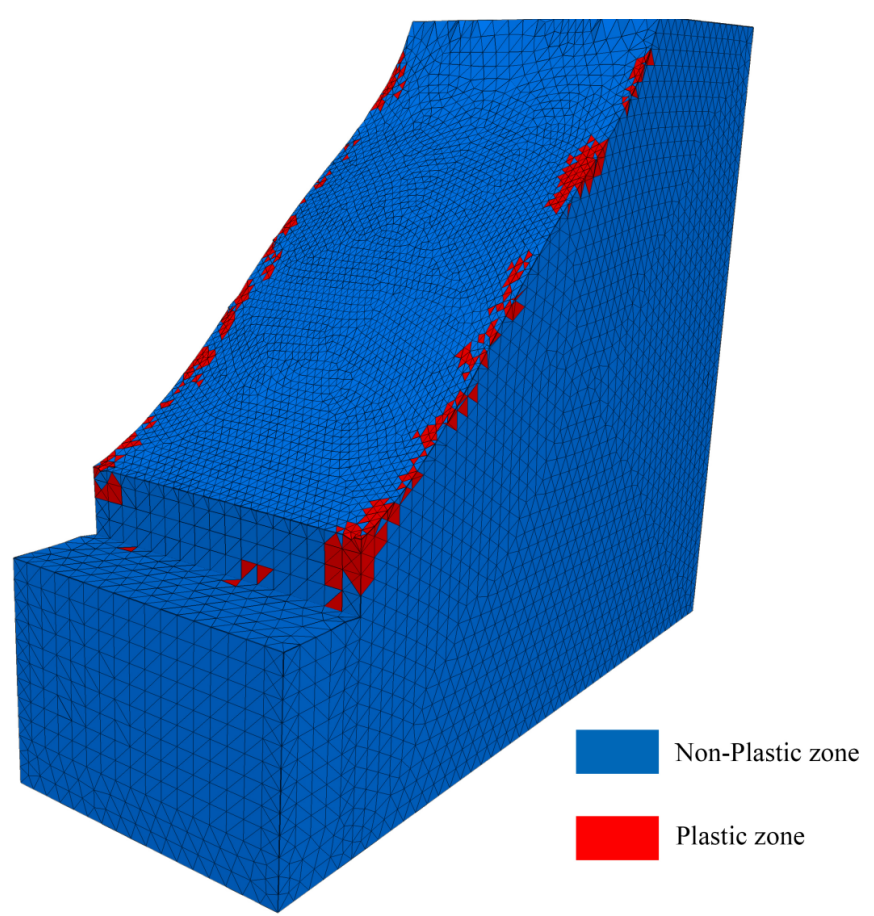

Figure 8. The plastic zone after removing the landslide body.

Table 2 and Figure 8 show that the proposed LREM can accurately evaluate and predict the slope stability and eliminate the unstable factors when the slope is unstable.

Table 2. Comparison of slope stability analyzed by (1) LREM and (2) FDM and SRM (the FOS is used to determine the stability of the slope, i.e., when FOS $>1$, the slope is stable; when FOS $\leq 1$, the slope is unstable).

\begin{tabular}{cccccccccc}
\hline Slicing Mining & 1st & 2nd & 3rd & 4th & 5th & 6th & 7th & 8th & $\begin{array}{c}\text { After the } \\
\text { 1st Landslide }\end{array}$ \\
(After Exploiting the $i$ th Layer) & Layer & Layer & Layer & Layer & Layer & Layer & Layer & Layer & Lable \\
\hline Slope Stability (LREM) & Stable & Stable & Stable & Stable & Stable & Stable & Stable & Unstable & Stable \\
Safety Factors (FDM+SRM) & 1.49 & 1.43 & 1.35 & 1.27 & 1.19 & 1.12 & 1.05 & 1 & 1.39 \\
\hline
\end{tabular}

Figure 9 shows the contours of the displacement before and after removing the landslide body. As shown in Figure 9, the displacement before the transfer of the physical field variables is compared with the displacement after the transfer of the physical field variables. After removing the landslide body, the residual mesh and the updated mesh accurately inherit the physical field variables of the old mesh, which indicates that the proposed adaptive local remeshing technique reduces the scale of remeshing and retains the original nodes as much as possible. In the process of transferring physical field variables, the errors due to interpolation are small. 


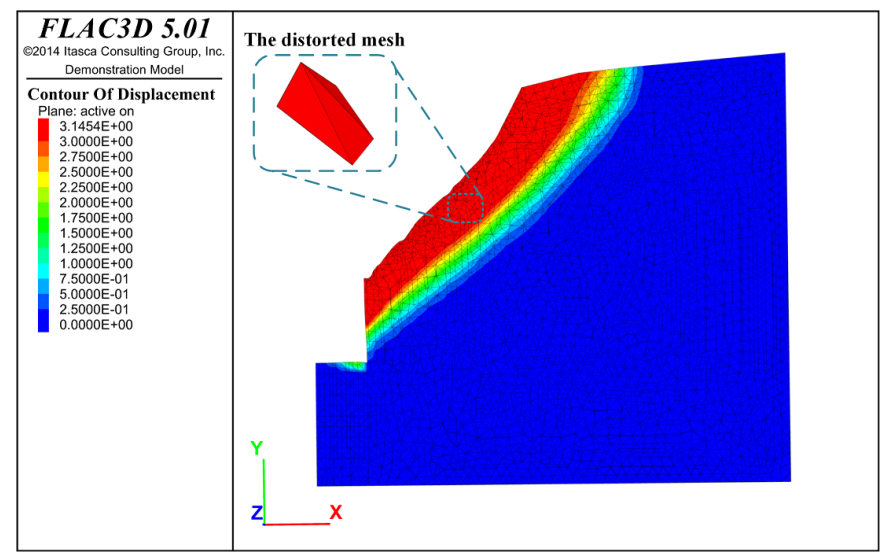

(a) Before removing the landslide body

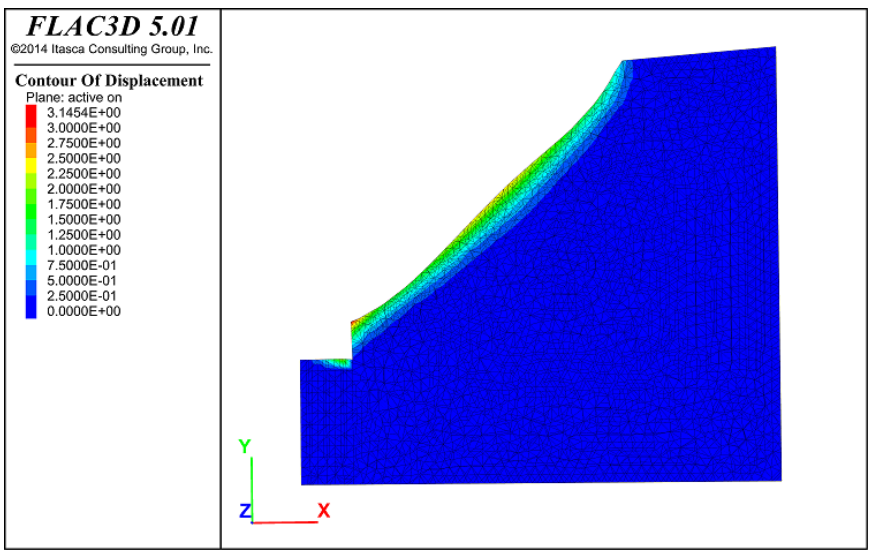

(b) After removing the landslide body

Figure 9. Comparison of the displacement before and after removing the landslide body.

\section{Application Case}

\subsection{Geological and Engineering Background}

\subsubsection{Geology}

The Yanqianshan Iron Mine is located in Anshan City, Liaoning Province, China (Figure 10a). The rock masses in the mining area are composed mainly of mixed granite, phyllite, and quartzite. The quartzite is hard and constitutes the east-west side of the slope. The granite rock is a massive structure.

The outcropped strata in the mining area include Anshan Formation, Liaohe Formation, and Quaternary metamorphic rocks, although the rock strata are mainly composed of Anshan metamorphic rocks. The Anshan Formation has a thickness of more than $400 \mathrm{~m}$ and is divided into three sections, with quartzite in the middle and phyllite on either side. There is an unconformable contact face between the two groups. The Anshan and Liaohe Formations have dip angles of approximately $70^{\circ}$ and $50^{\circ}$, respectively. In addition, in the Quaternary strata of the mining area, the thickness of the artificial accumulation layer is the highest, and the thickness of the slide rock layer is the lowest.

The basic structural pattern of the mining area is a steep monoclinic structure trending in the direction of $270^{\circ} \sim 300^{\circ}$, with a dip direction in the northeast or southwest and a dip angle in the range of $70^{\circ} \sim 88^{\circ}$ [30]. The faults in the mining area can be divided into strike-slip, oblique, and transverse faults. The interior of the ore body contains a host of strike-slip faults, causing significant damage to the ore body. The middle of the faults is mostly filled with neutral rocks. Oblique faults are the most widely developed faults in mining areas, and they often intersect with strike-slip faults. Most of them are filled with phyllite, causing significant damage to the rock mass and the ore body. The transverse faults intersect strike-slip and oblique faults. 


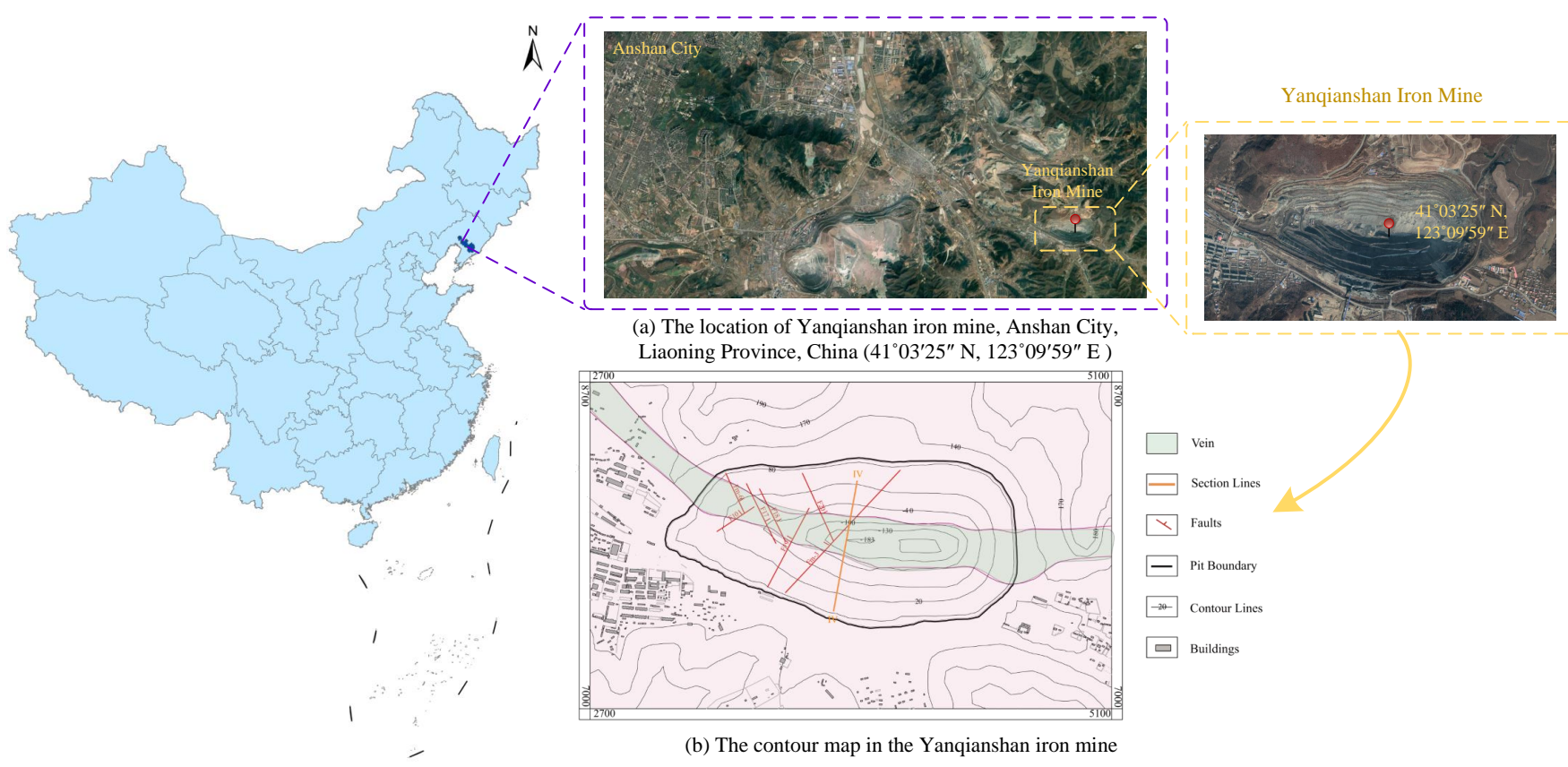

Figure 10. The geographic and topographic maps in the Yanqianshan iron mine (the geographic map comes from https: / / earth.google.com, accessed on 10 April 2021).

\subsubsection{Engineering Background}

Mining has been taking place in the Yanqianshan Iron Mine for over fifty years. According to the location of the ore body and the mining time, the Yanqianshan Iron Mine can be divided into three stages. The first stage is open-pit mining, which started in 1960 and ended in 2012. After open-pit mining, the size of the mine pit formed was large; since 2012, transitional ore body mining has been carried out, and the main ore bodies of the mine are on the west, east, and north sides. The ore body on the north side of the pit is underground mined for the ore body below the bottom of the pit after the end of the transition period, and the mining depth will not exceed $-500 \mathrm{~m}$.

\subsection{Computational Model and Parameters}

\subsubsection{Computational Model}

According to the contour map of the Yanqianshan Iron Mine (Figure 10b), a threedimensional mesh model (Figure 11) is established based on the representative Section Line IV. The model has a large size: $2560 \mathrm{~m}$ in length and $724 \mathrm{~m}$ in height. If the model is created by means of equal-sized tetrahedral meshes, the number of elements will be large, and the calculation efficiency will be unsatisfactory. To reduce the number of elements, smaller tetrahedral meshes are used near the excavation site, and larger tetrahedral meshes are used elsewhere.

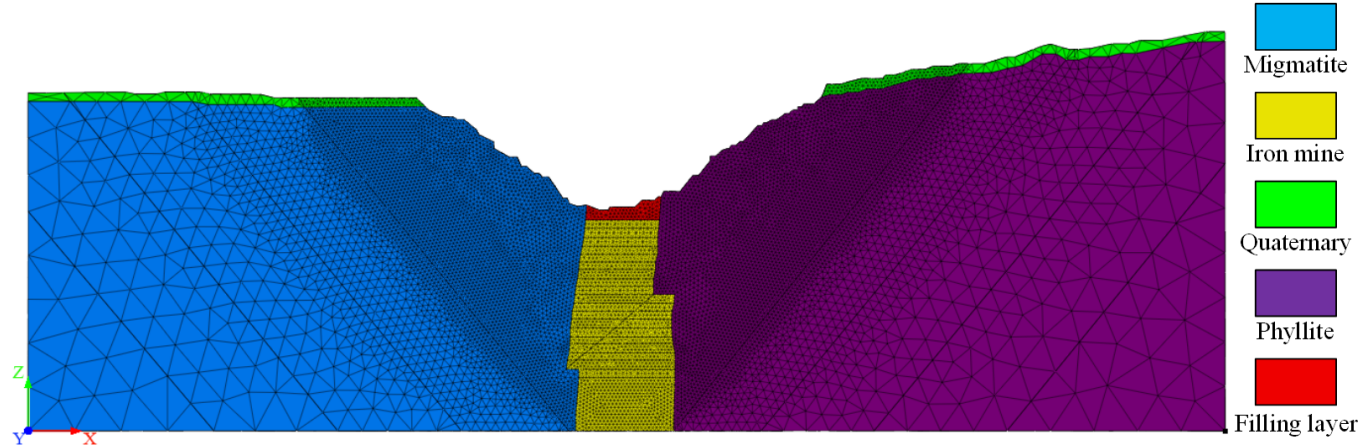

Figure 11. The tetrahedral mesh model (Section Line IV in Figure 10b). 
The boundary condition in the numerical analysis is set mainly in terms of the stress, displacement, and their combination. In this study, the displacement boundary condition is used to constrain the node movement, where the full constraint is set at $z=-600 \mathrm{~m}$, i.e., the displacement in the three directions is limited. At $x=0 \mathrm{~m}$ and $x=2560 \mathrm{~m}$, the displacement constraint in the $x$-direction is set; at $y=0 \mathrm{~m}$ and $y=300 \mathrm{~m}$, the displacement constraint in the $y$-direction is set; the remaining positions are free boundaries. The initial stress field is obtained by setting the magnitude of the acceleration due to gravity as $-10 \mathrm{~m} / \mathrm{s}^{2}$, the constitutive model is Mohr-Coulomb, and the maximum unbalanced force ratio is set as $1 \times 10^{-5}$. The dimensions of each excavation are listed in Table 3 .

Table 3. Dimensions of each excavation.

\begin{tabular}{|c|c|c|c|c|c|c|c|c|c|c|c|c|}
\hline Slicing Mining & $\begin{array}{c}\text { 1st } \\
\text { Layer }\end{array}$ & $\begin{array}{l}\text { 2nd } \\
\text { Layer }\end{array}$ & $\begin{array}{c}\text { 3rd } \\
\text { Layer }\end{array}$ & $\begin{array}{c}\text { 4st } \\
\text { Layer }\end{array}$ & $\begin{array}{c}5 s t \\
\text { Layer }\end{array}$ & $\begin{array}{c}\text { 6st } \\
\text { Layer }\end{array}$ & $\begin{array}{c}7 \mathrm{st} \\
\text { Layer }\end{array}$ & $\begin{array}{c}\text { 8st } \\
\text { Layer }\end{array}$ & $\begin{array}{c}\text { 9st } \\
\text { Layer }\end{array}$ & $\begin{array}{l}\text { 10th } \\
\text { Layer }\end{array}$ & $\begin{array}{l}\text { 11th } \\
\text { Layer }\end{array}$ & $\begin{array}{l}\text { 12th } \\
\text { Layer }\end{array}$ \\
\hline Thickness (m) & 17.5 & 19.7 & 18.9 & 17.0 & 16.5 & 15.2 & 20.8 & 15.5 & 17.9 & 18.6 & 16.6 & 16.9 \\
\hline Width (m) & 158.1 & 158.2 & 159.7 & 163.1 & 163.9 & 163.7 & 163.3 & 164.3 & 167.2 & 212.9 & 213.8 & 213.7 \\
\hline Length (m) & 300 & 300 & 300 & 300 & 300 & 300 & 300 & 300 & 300 & 300 & 300 & 300 \\
\hline
\end{tabular}

\subsubsection{Computational Parameters}

The rock mass of the slope is composed mainly of phyllite on the south slope, migmatite on the north slope, surface Quaternary strata, iron ore, and a filling layer. Table 4 lists the physical and mechanical parameters of the rock mass in this area based on the design of the sublevel caving mining project of the Yanqianshan Iron Mine.

Table 4. Mechanical parameters of rock masses and soil in Yanqianshan Iron Mine (where $C$ is the cohesion, $\varphi$ is the internal friction angle, $E$ is the young's modulus, $\mu$ is the Poisson's ratio, $\rho$ is the density).

\begin{tabular}{cccccc}
\hline Name & $\boldsymbol{C}(\mathbf{M P a})$ & $\boldsymbol{\varphi}\left(^{\circ}\right)$ & $\boldsymbol{E}(\mathbf{G P a})$ & $\boldsymbol{\mu}$ & $\boldsymbol{\rho}\left(\mathbf{k g} / \mathbf{m}^{\mathbf{3}}\right)$ \\
\hline Iron Mine & 0.95 & 41 & 40 & 0.2 & 3100 \\
Migmatite & 0.45 & 39 & 18 & 0.23 & 2670 \\
Phyllite & 0.365 & 36.5 & 15 & 0.25 & 2740 \\
Quaternary & 0.2 & 25 & 0.05 & 0.3 & 1980 \\
Filling Layer & 0 & 24 & 0.06 & 0.32 & 1550 \\
\hline
\end{tabular}

\subsection{Process of Numerical Modeling}

The slope loses stability when excavated to the fifth, seventh, eighth, tenth and eleventh layers, which is consistent with the slope failure characteristics of the sublevel caving mining described in Section 2. The slope of the Yanqianshan iron mine is in a stable state when excavating the first four layers. When excavating the fifth layer, the slope loses stability, and then when excavating the sixth layer, the slope is restored to a stable state. The slope of the Yanqianshan iron mine has undergone a cycle of stability-instability-stability. In the next seventh to twelfth layers of the vein excavation process, with the gradual increase in the mining depth, the above process occurs repeatedly.

\subsubsection{Modeling of the Excavation of the First to Fourth Layers}

In the numerical simulation, it is more convenient to simulate the filling layer during excavation. During the first excavation, the filling layer (the first layer) was removed, and the mechanical parameters of the second layer were changed to those of the filling layer, indicating that the filling layer moved down to the position of the second layer after the ore body of the second layer was excavated. In Figure 11, the ore body and the filling layer make up twenty layers in total; however, according to the mining plan, we only simulated the excavation of the first twelve layers. 
In the initial stage of ore body excavation, for example, during the excavation of the third layers, the displacement of the free surface of the slope is less, and most of the displacement is concentrated in the filling layer. Because the original filled ore body was excavated, the unloading effect and the surrounding rock stress caused the uplift of the ore body; thus, the displacement of this part is larger (Figure 12a).

The stress release due to the excavation of the third layer is less, the stress concentration of the slope foot is not high, the plastic zone of the slope is small (Figure 12b), the degree of shear deformation is not high, and the shear strain increment zone is concentrated mainly in the filling layer (Figure 12c). The stability of the slope is high, and the convergence of the numerical calculation is faster.

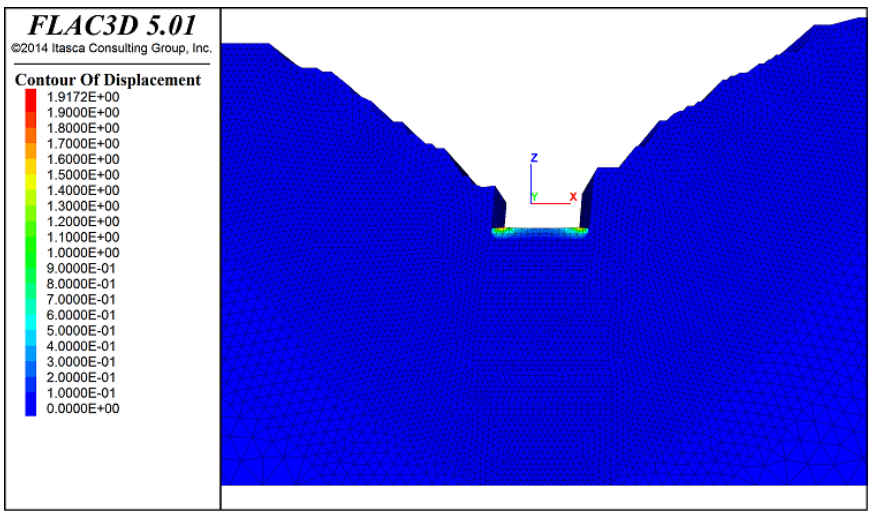

(a) Contour of displacement

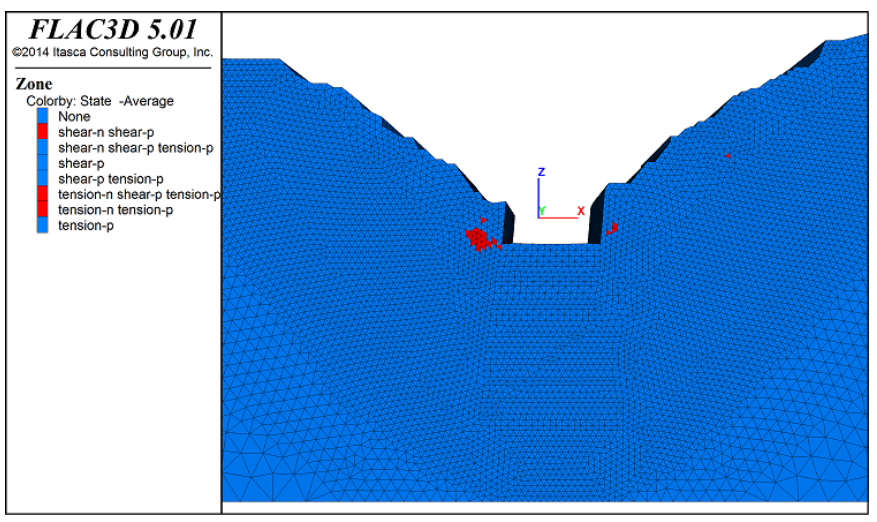

(b) The plastic zone

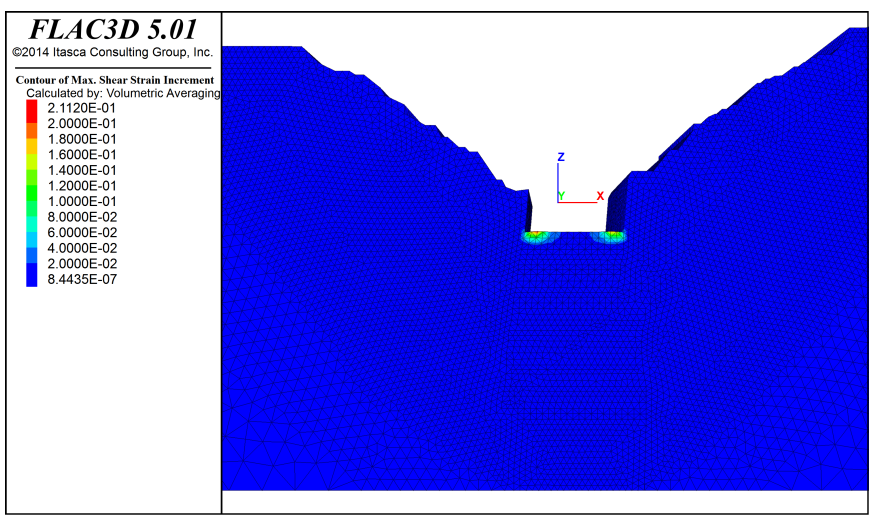

(c) Contour of maximum shear strain increment

Figure 12. Numerical results after mining the third layer.

With the increase in the excavation depth, the lateral unloading increases, and the displacement of the slope increases. The displacement of the slope foot, shown in Figure 13a, 
reaches $2.6 \mathrm{~m}$. The internal stress of the slope changes, particularly in the direction of the maximum principal stress, thus increasing the maximum principal stress near the foot of the slope, decreasing the minimum principal stress, and leading to stress concentration near the foot of the slope due to the stress difference. The penetration of the maximum shear strain increment belt appears at the foot of the slope, resulting in shear failure at the foot of the slope. The tension zone exists at the shoulder of the slope, leading to tensile failure of the meshes in this part of the model, as shown in Figures 13b and 14a.

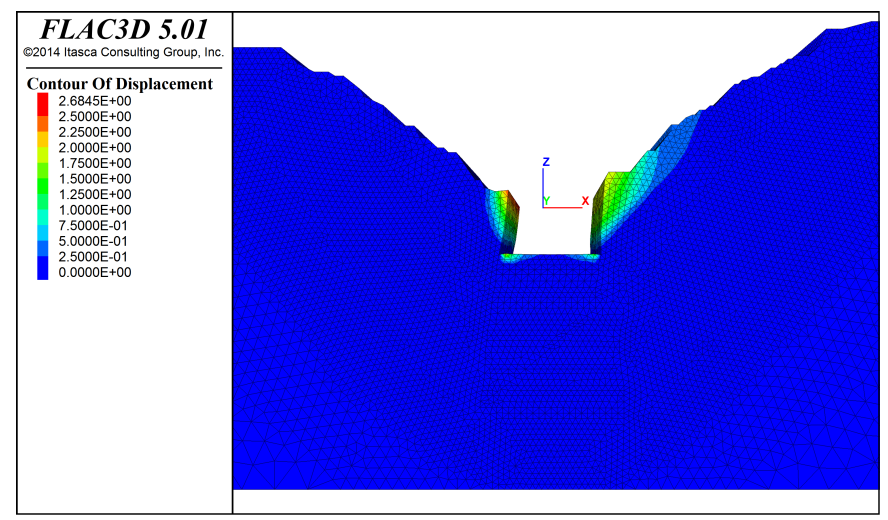

(a) Contour of displacement

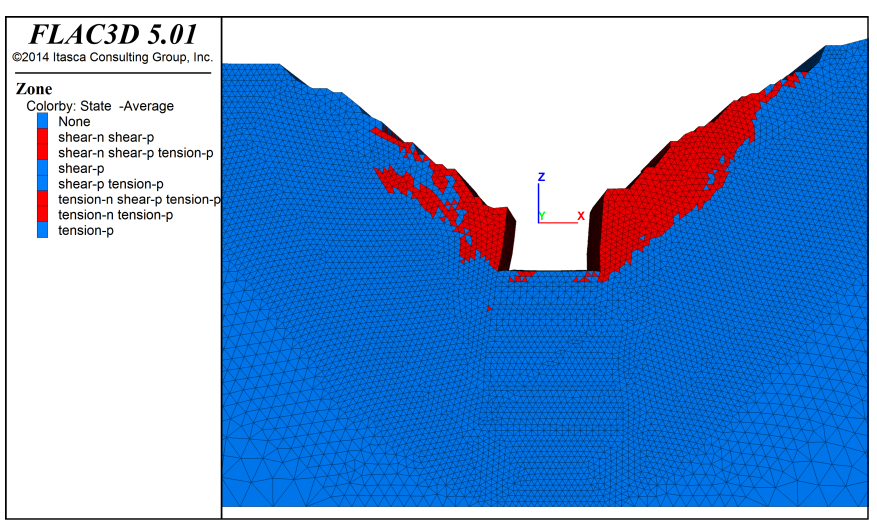

(b) The plastic zone

Figure 13. Numerical results after mining the fifth layer.

\subsubsection{Modeling of the Excavation of the Fifth and Sixth Layers}

When the fifth layer is excavated, both the north and the south slopes have formed steep cliffs, and they are easily unstable because of gravity; therefore, penetration of the maximum shear strain increment belt appears in the south slope and the north slope (Figure 14a). At this time, both the north and south slopes have distorted meshes, and the numerical calculation is not convergent. It is necessary to use the remeshing method proposed in this paper to simulate the slope instability. As shown in Figure 14b, there is no penetration zone, and the calculation converges. Therefore, the slope is determined to be in a stable state after the simulated landslide.

By comparing Figures $13 \mathrm{~b}$ and $14 \mathrm{a}$, we find that the range of the maximum shear strain increment zone is lower than that of the plastic zone. The maximum shear strain increment belt method is used to determine the slide surface and simulate a landslide to produce a converging calculation. Therefore, this method is more accurate as a criterion for judging the unstable state of the slope, it is safer to regard the nonpenetration of the plastic zone as the criterion for judging the stable state of the slope, and it also proves that the penetration of the plastic zone is not an adequate condition for slope instability but a necessary condition. 


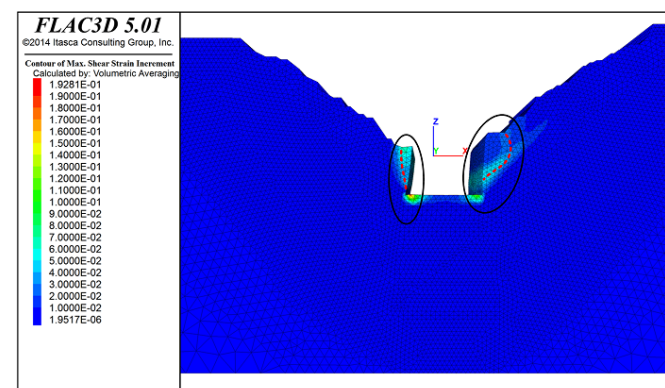

(a) Contour of maximum shear strain increment after mining the fifth layer

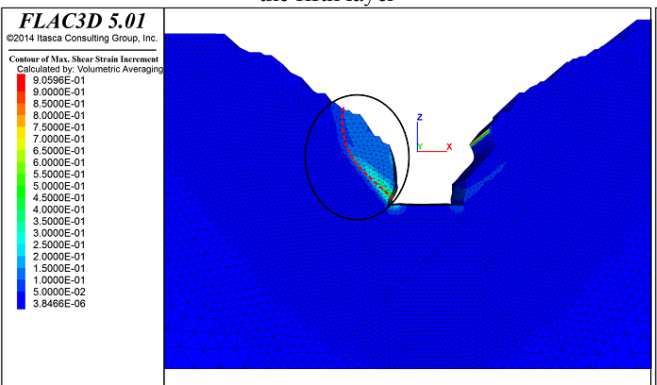

(c) Contour of maximum shear strain increment after mining the seventh layer

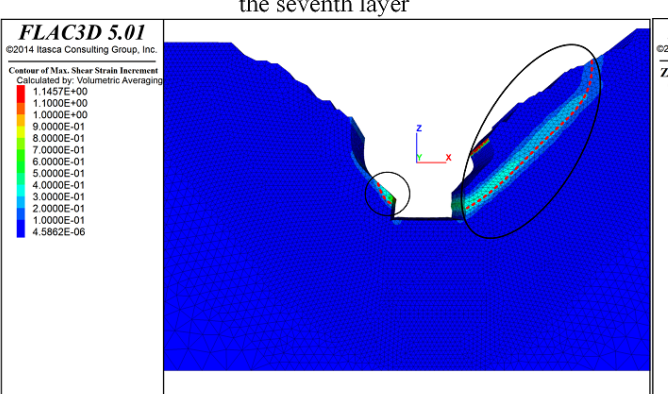

(e) Contour of maximum shear strain increment after mining the eighth layer

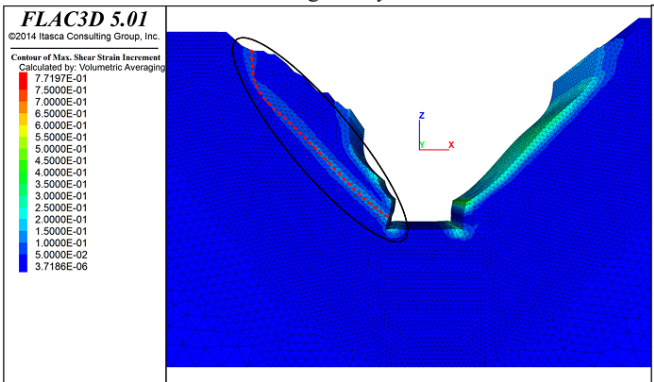

(g) Contour of maximum shear strain increment after mining the tenth layer

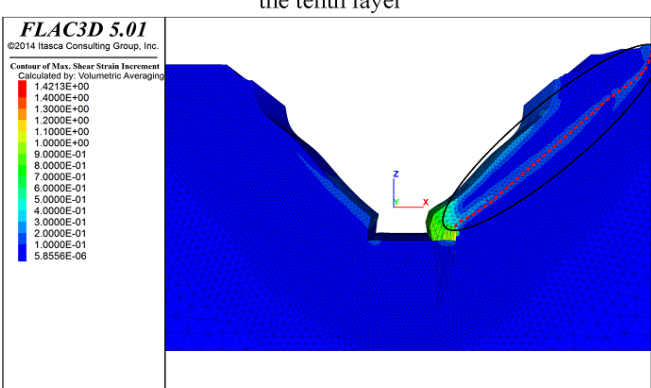

(i) Contour of maximum shear strain increment after mining the eleventh layer

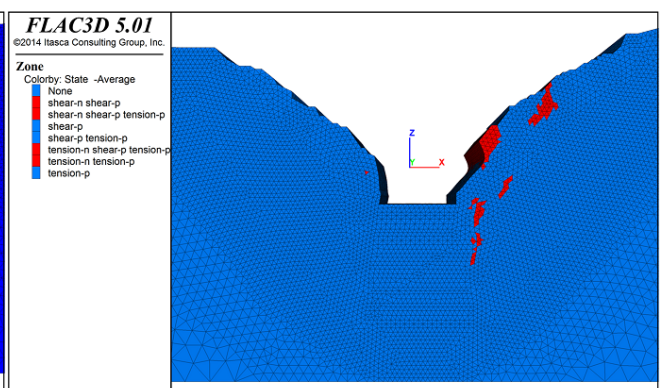

(b) The plastic zone after the first landslide simulation

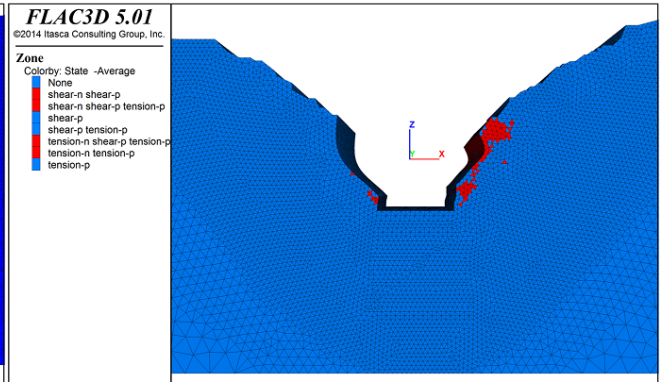

(d) The plastic zone after the second landslide simulation

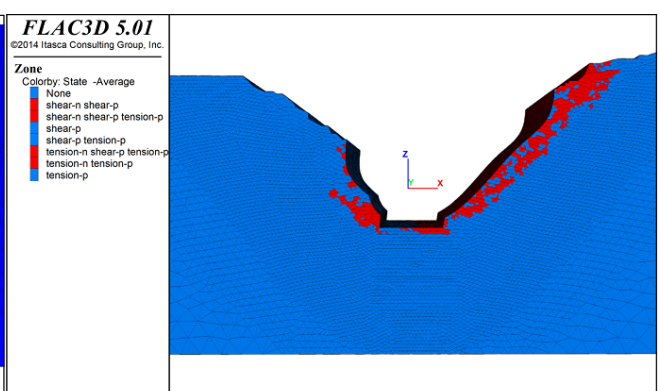

(f) The plastic zone after the third landslide simulation

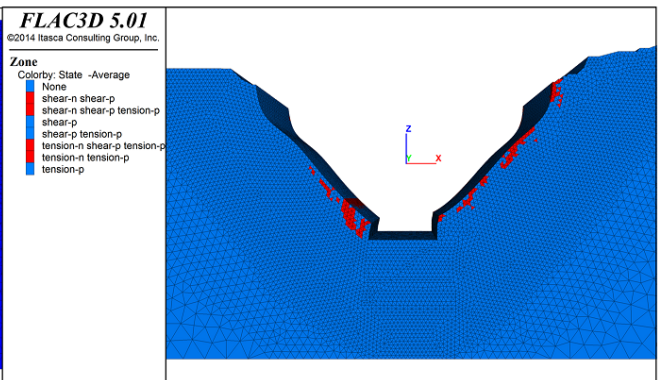

(h) The plastic zone after the fourth landslide simulation

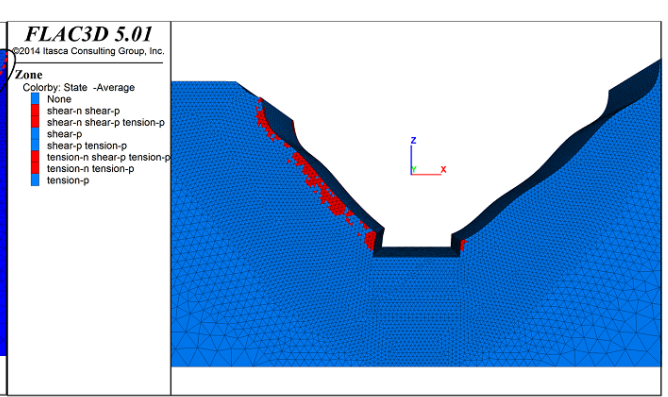

(j) The plastic zone after the fifth landslide simulation

Figure 14. The contour of maximum shear strain increment and the plastic zone. (The maximum shear strain increment is the criterion for judging slope instability after mining the ith layer, and the plastic zone is the criterion for slope stability after landslide). 


\subsubsection{Modeling of the Excavation of the Seventh to Twelfth Layers}

After the excavation of the seventh layer, the displacement of the south slope continues to increase, and the deformation degree of the mesh increases rapidly, leading to the penetration of the maximum shear strain increment belt of the slope and the instability of the south slope (Figure 14c). After the simulation of a landslide, the unstable part on the south slope is eliminated, and the plastic zones on the north and south slopes are reduced (Figure 14d).

When the eighth layer is excavated, the way that the south slope is destroyed is similar to that of when the fifth layer was excavated. The earth pressure inside the north slope is relatively high because of the excavation at the foot of the slope, and this is the penetration of the maximum shear strain increment belt. As shown in Figure 14e, the numerical calculation is not convergent at this time, indicating that a landslide occurs. Therefore, the landslide is simulated by the method proposed in this paper.

After the third landslide, the north and south slopes were in a stable state with a relatively high safety factor. The excavation of the ninth layer ore body had little effect on the stability of the north and south slopes. Figure 15 shows the plastic zone of the slope after excavation. Although penetration of the plastic zone occurs, the numerical calculation converges. This shows that the slope is in a critical state.

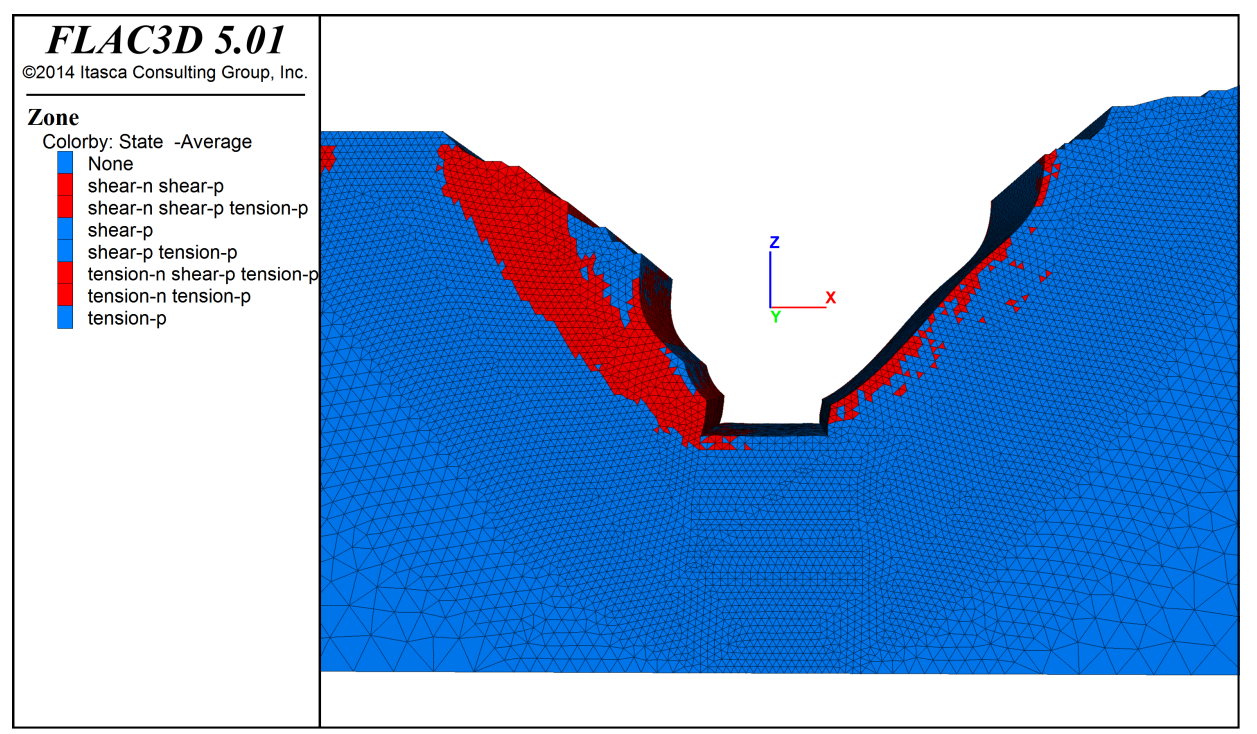

Figure 15. The plastic zone after mining the ninth layer.

According to the excavation of the seventh and eighth layers, the excavation of the ore body at this stage has a great influence on the stability of the slope: with the increase in the excavation depth, the north and south slopes alternately lose stability. This behavior is repeated when excavating the tenth and eleventh layers. These layers are located near the fault, so the slope is less stable there. When the tenth layer is excavated, the numerical calculation does not converge, and the south slope is unstable. The penetration of the maximum shear strain increment belt occurs (Figure 14e). After simulating the landslide on the southern slope, the plastic zone of the slope did not penetrate the slope completely, and the slope was stable (Figure 14f). When excavation is performed on the eleventh layer, the top rock mass of the ore body loses the support of the ore layer, so the rock body collapses and causes a landslide, the penetration of the maximum shear strain increment belt occurs and the meshes exhibit obvious distortion. The numerical calculation does not converge, and the slope is unstable (Figure 14g). After simulating the landslide on the southern slope, the plastic zone of the slope did not penetrate the slope completely, and the slope was stable (Figure 14h).

When the eleventh layer of the vein is excavated, the maximum shear strain increment belt of the south slope is not completely penetrated (Figure 14g), and the numerical 
calculation converges, leaving hidden dangers for the subsequent stability of the south slope. Therefore, the south slope is already in a critical state when excavating the twelfth layer (Figure 16).

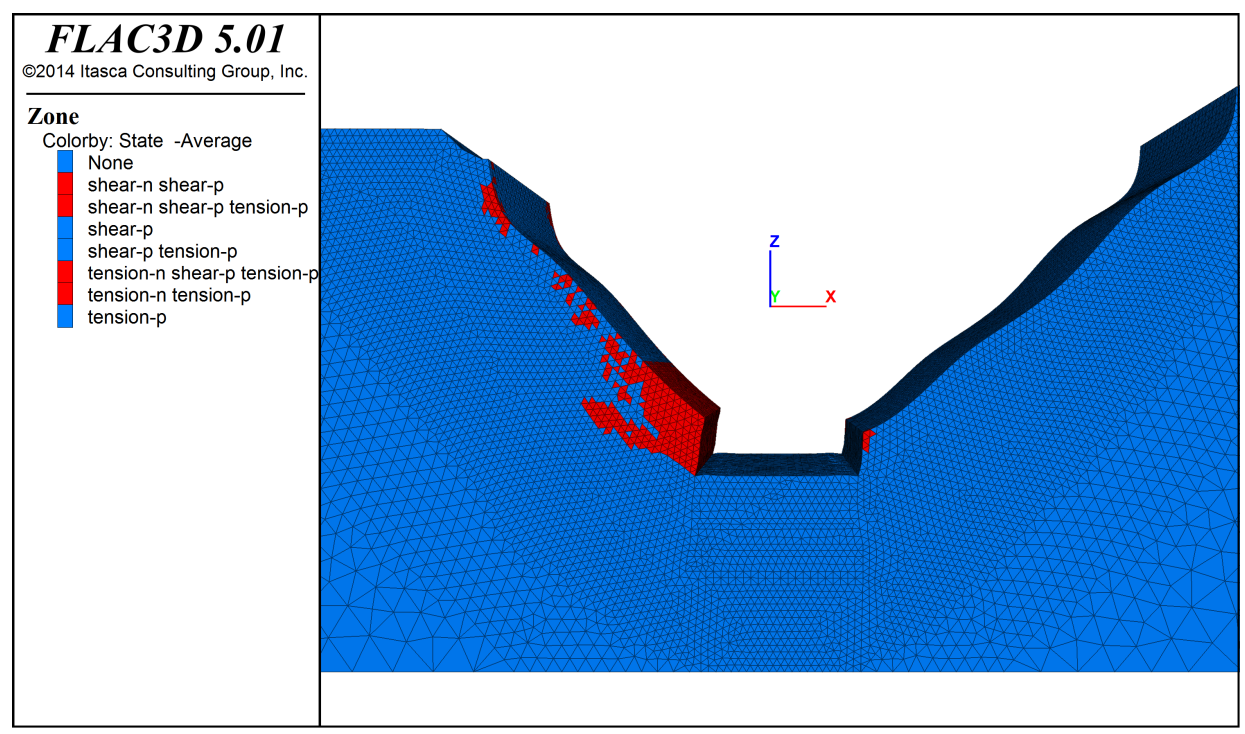

Figure 16. Contour of maximum shear strain increment after mining the twelfth layer.

\section{Discussion}

\subsection{Advantages of the Proposed Method for Analyzing Progressive Slope Failure}

The LREM is proposed to investigate the progressive slope failure induced by sublevel caving mining in large-scale rock slopes. The progressive slope failure induced by sublevel caving mining in a large-scale rock slope can be simulated effectively. The DEM for block systems is widely used to simulate discontinuous rock mass movement and failure. However, for the modeling of large-scale rock slopes, the DEM for block systems is quite computationally expensive or may even fail. In contrast, the LREM is based on the FDM, which is more efficient than the DEM.

The proposed method is able to address the problem of mesh distortion in conventional FDM modeling. In the proposed LREM, to address the problem of mesh distortion in modeling using the FDM, an adaptive local remeshing technique is proposed to regenerate the mesh, resulting in an updated mesh that satisfies the quality requirements for FDM modeling.

Compared with the errors introduced by the frequent updating of the mesh of the entire model, the adaptive local remeshing technique effectively reduces the errors. In the proposed adaptive local remeshing technique, on the basis of the slip surface determined by the maximum shear strain increment belt method, the zone of the distorted mesh is adaptively identified, and the landslide body is removed. Then, the updated mesh is regenerated by the local remeshing technique, and the physical field variables of the original mesh are transferred to the regenerated mesh. Compared with the frequent updating of the mesh of the entire model, the proposed adaptive local remeshing technique reduces the frequency and scale of remeshing and retains the original nodes, which effectively reduces the errors due to interpolation in the process of the transfer of physical field variables.

In the proposed LREM, the slip surface can be accurately determined. The maximum shear strain increment belt method is used to search for the slip surface and evaluate whether the rock slope is unstable. In the simulation process, we found that the numerical calculation is necessarily nonconvergent when penetration of the maximum shear strain increment belt occurs, whereas it is not necessarily nonconvergent when penetration of the plastic zone occurs. Moreover, the maximum shear strain increment zone is smaller than that of the plastic zone. This indicates that the maximum shear strain increment belt 
method is more accurate than the approach using the penetration of the plastic zone, which is widely regarded as the criterion for slope failure.

\subsection{Disadvantages of the Proposed Method for Analyzing Progressive Slope Failure}

As given in Section 2, during excavation, the thickness of the filling layer should be kept within a reasonable range according to the actual situation. However, we took the thickness of the filling layer as the thickness of the excavated mining layer based on experience, thus ensuring that the thickness of the filling layer is a constant. We did not calculate the optimal thickness of the filling layer according to the actual situation and the drawing ellipsoid theory.

For the numerical modeling of the progressive slope failure induced by the sublevel caving mining in the Yanqianshan Iron Mine, the model of the Yanqianshan Iron Mine was simplified; only a representative geological section model was established, and the hydrogeological conditions and anisotropic discontinuities of the rock were not considered. In addition, in the sublevel caving method, blasting has an impact on the stability of the slope, surrounding rock and filling layer. The blasting vibration may cause damage to the structural plane and reduce the shear strength of the rock mass, which is not considered in this paper due to insufficient data.

\subsection{Outlook and Future Work}

In the proposed LREM, it is still necessary to conduct repeated interpolation in the process of remeshing, resulting in accuracy loss. For this problem, there are two solutions. First, more accurate interpolation methods can be developed to reduce the error caused by interpolation. Second, it is more accurate to locate the positions of the distorted meshes in the process of remeshing, which can reduce the remeshing of undistorted meshes. Moreover, we believe that this idea can be applied to the remeshing of meshes with different geometries. At present, programs for meshes with different geometries have not been developed and will be completed in the future.

However, for the progressive slope failure induced by sublevel caving mining, we can couple the continuum-based method with the discontinuum-based method. For example, the smoothed point interpolation method [31] is used for the vulnerable part, and the FDM is used for the stable part. This method not only avoids the distorted mesh problem but also reduces the computational expense compared with discontinuum-based methods.

\section{Conclusions}

The progressive slope failure induced by sublevel caving mining is a cyclic process that cycles between an intermittent instability state, resulting in rock mass failure with large deformation and displacement in the slope. Numerical methods are widely used to investigate the above phenomenon. However, conventional numerical methods have issues in simulating the process of progressive slope failure. The DEM for block systems is quite computationally expensive for large-scale slope models, and the FDM has a mesh distortion problem when simulating progressive slope failure. To address the above problems, the LREM is proposed to simulate the process of slope failure induced by sublevel caving mining. The effectiveness of the LREM is verified by comparing it with the FDM and SRM. Moreover, the proposed LREM is successfully applied to investigate the progressive slope failure of the Yanqianshan Iron Mine induced by sublevel caving mining. The proposed method is thus applicable and capable of investigating the progressive slope failure induced by sublevel caving mining.

Author Contributions: Conceptualization, J.T., Y.Z., G.M., N.X.; methodology, J.T., Y.Z., G.M., N.X.; writing—original draft preparation, J.T., G.M.; writing—review and Editing, J.T., G.M. All authors have read and agreed to the published version of the manuscript. 
Funding: This work was supported by the Natural Science Foundation of China (Grant Numbers 11602235 and 41772326) and the Fundamental Research Funds for the Central Universities (2652018091).

Institutional Review Board Statement: Not applicable.

Informed Consent Statement: Not applicable.

Data Availability Statement: The data presented in this study are available on request from the corresponding author.

Acknowledgments: The authors would like to thank the editor and the reviewers for their contributions.

Conflicts of Interest: The authors declare no conflict of interest.

\author{
Abbreviations \\ The following abbreviations are used in this manuscript: \\ LREM Finite Difference Modeling Method using Adaptive Local Remeshing \\ FLAC Fast Lagrangian Analysis of Continua \\ DEM Discrete Element Method \\ FDM Finite Difference Method \\ FEM Finite Element Method \\ FOS Factor of Safety \\ SRM Strength Reduction Method \\ MPM Material Point Method
}

\title{
References
}

1. Huang, C.; Lo, C.; Jang, J.; Hwu, L. Internal soil moisture response to rainfall-induced slope failures and debris discharge. Eng. Geol. 2008, 101, 134-145. [CrossRef]

2. Mohammadi, S.; Taiebat, H. Finite element simulation of an excavation-triggered landslide using large deformation theory. Eng. Geol. 2016, 205, 62-72. [CrossRef]

3. Govender, N.; Wilke, D.N.; Kok, S.; Els, R. Development of a convex polyhedral discrete element simulation framework for NVIDIA Kepler based GPUs. J. Comput. Appl. Math. 2014, 270, 386-400. [CrossRef]

4. Govender, N.; Wilke, D.N.; Kok, S. Collision detection of convex polyhedra on the NVIDIA GPU architecture for the discrete element method. Appl. Math. Comput. 2015, 267, 810-829. [CrossRef]

5. Souley, M.; Homand, F. Stability of jointed rock masses evaluated by UDEC with an extended Saeb-Amadei constitutive law. Int. J. Rock Mech. Min. Sci. Geomech. Abstr. 1996, 33, 233-244. [CrossRef]

6. Li, X.; Wu, Y.; He, S.; Su, L.J. Application of the material point method to simulate the post-failure runout processes of the Wangjiayan landslide. Eng. Geol. 2016, 212. [CrossRef]

7. Wang, B.; Vardon, P.; Hicks, M. Rainfall-induced slope collapse with coupled material point method. Eng. Geol. 2018, 239. [CrossRef]

8. Conte, E.; Pugliese, L.; Troncone, A. Post-failure stage simulation of a landslide using the material point method. Eng. Geol. 2019, 253, 149-159. [CrossRef]

9. Bakhtavar, E. Transition from Open-Pit to Underground in the Case of Chah-Gaz Iron Ore Combined Mining. J. Min. Sci. 2013, 49, 955-966. [CrossRef]

10. Elmo, D.; Vyazmensky, A.; Stead, D.; Rance, J.R. A Hybrid FEM/DEM Approach to Model the Interaction between Open-Pit and Underground Block-Caving Mining; Rock Mechanics: Meeting Society's Challenges and Demands, Vols 1 and 2: Vol: Fundamentals, New Technologies \& New Ideas; Vol 2: Case Histories; CRC Press: Boca Raton, FL, USA, 2007; pp. 1287-1294. [CrossRef]

11. Vyazmensky, A.; Stead, D.; Elmo, D.; Moss, A. Numerical Analysis of Block Caving-Induced Instability in Large Open Pit Slopes: A Finite Element/Discrete Element Approach. Rock Mech. Rock Eng. 2010, 43, 21-39. [CrossRef]

12. Sun, C.; Chai, J.; Xu, Z.; Qin, Y.; Chen, X. Stability charts for rock mass slopes based on the Hoek-Brown strength reduction technique. Eng. Geol. 2016, 214, 94-106. [CrossRef]

13. Zienkiewicz, O.; Humpheson, C.; Lewis, R. Associated and nonassociated visco-plasticity and plasticity in soil mechanics. Geotechnique 1975, 25, 671-689. [CrossRef]

14. Kumsar, H.; Aydan, O.; Ulusay, R. Dynamic and static stability assessment of rock slopes against wedge failures. Rock Mech. Rock Eng. 2000, 33, 31-51. [CrossRef]

15. Zhao, Y.; Yang, T.; Bohnhoff, M.; Zhang, P.; Yu, Q.; Zhou, J.; Liu, F. Study of the Rock Mass Failure Process and Mechanisms During the Transformation from Open-Pit to Underground Mining Based on Microseismic Monitoring. Rock Mech. Rock Eng. 2018, 51, 1473-1493. [CrossRef] 
16. Woo, K.S.; Eberhardt, E.; As, A. Characterization and empirical analysis of block caving induced surface subsidence and macro deformations. In Proceedings of the 3rd Canada-US Rock Mechanics Symposium and 20th Canadian Rock Mechanics Symposium, Toronto, ON, Canada, 9-15 May 2009; pp. 1-10.

17. Janelid, I.; Kvapil, R. Sublevel caving. Int. J. Rock Mech. Min. Sci. 1966, 3, 129-153. [CrossRef]

18. Zhou, X.P.; Cheng, H. Stability analysis of three-dimensional seismic landslides using the rigorous limit equilibrium method. Eng. Geol. 2014, 174, 87-102. [CrossRef]

19. Liu, Z.; Liu, J.; Bian, K.; Ai, F. Three-dimensional limit equilibrium method based on a TIN sliding surface. Eng. Geol. 2019, 262, 105325. [CrossRef]

20. Saiang, D. Stability analysis of the blast-induced damage zone by continuum and coupled continuum-discontinuum methods. Eng. Geol. 2010, 116, 1-11. [CrossRef]

21. Zheng, W.; Zhuang, X.; Tannant, D.D.; Cai, Y.; Nunoo, S. Unified continuum/discontinuum modeling framework for slope stability assessment. Eng. Geol. 2014, 179, 90-101. [CrossRef]

22. Tomas, R.; Cuenca, A.; Cano, M.; Garcia-Barba, J. A graphical approach for slope mass rating (SMR). Eng. Geol. 2012, 124, 67-76. [CrossRef]

23. Basahel, H.; Mitri, H. Application of rock mass classification systems to rock slope stability assessment: A case study. J. Rock Mech. Geotech. Eng. 2017, 9, 5-21. [CrossRef]

24. Mohammad, A.; Yaser, A.N.; Lila, R.; Haluk, A.; Jafar, R.; Reza, D.; Amir, R. Application of the modified Q-slope classification system for sedimentary rock slope stability assessment in Iran. Eng. Geol. 2019, 264, 105349. [CrossRef]

25. Möller, T. A Fast Triangle-triangle Intersection Test. J. Graph. Tools 1997, 2, 25-30. [CrossRef]

26. Tropp, O.; Tal, A.; Shimshoni, I. A fast triangle to triangle intersection test for collision detection. Comput. Animat. Virtual Worlds 2006, 17, 527-535. [CrossRef]

27. Shen, H.; Heng, P.; Tang, Z. A Fast Triangle-triangle Overlap Test Using Signed Distances. J. Graph. Tools 2003, 8, 17-23. [CrossRef]

28. Guigue, P.; Devillers, O. Fast and Robust Triangle-Triangle Overlap Test Using Orientation Predicates. J. Graph. Tools 2003, 8, 25-32. [CrossRef]

29. Mei, G.; Tipper, J.C.; Xu, N. A Generic Paradigm for Accelerating Laplacian-Based Mesh Smoothing on the GPU. Arab. J. Sci. Eng. 2014, 39, 7907-7921. [CrossRef]

30. Xu, N.; Zhang, J.; Tian, H.; Mei, G.; Ge, Q. Discrete element modeling of strata and surface movement induced by mining under open-pit final slope. Int. J. Rock Mech. Min. Sci. 2016, 88, 61-76. [CrossRef]

31. Liu, G.R.; Zhang, G.Y. Edge-based smoothed point interpolation methods. Int. J. Comput. Methods 2011, 5, 621-646. [CrossRef] 